\title{
Molecular aspects of squaraine dyes aggregation and its influence on spectroscopic properties
}

\author{
Anna Kaczmarek-Kedziera ${ }^{1} \cdot$ Dariusz Kędziera $^{1}$
}

Received: 22 December 2015 / Accepted: 22 July 2016 / Published online: 10 August 2016

(C) The Author(s) 2016. This article is published with open access at Springerlink.com

\begin{abstract}
Molecular aggregates of two squaraine dyes of different ability for hydrogen-bond formation are investigated with computational chemistry tools. Oligomers up to hexamers are included into the present analysis. Potential energy surface scan for dimers and small oligomers indicates a preference for regular staircase and zig-zag structures. A decomposition of interaction energy of the dimers with SAPT0 procedure allows to notice a clear predominance of dispersion-bound structures in the case of 2,4-bis(4-dimethylaminophenyl)squaraine and susceptibility of the 2,4-bis(aminophenyl)squaraine for hydrogenbond formation, what is consistent with predictions based on molecular structure. An influence of aggregation on spectroscopic properties is analyzed. An elongation of the squaraine oligomer leads to a shift on the maximum absorption wavelength and an increase of the intensity of the signal. Moreover, in the case of the 2,4-bis(aminophenyl) squaraine, the new interaction-induced signals appear in the long-wavelength part of the UV-Vis spectrum.
\end{abstract}

Keywords DFT calculations · Squaraine dyes · Hydrogen bond $\cdot$ Intermolecular interactions $\cdot$ Absorption spectrum

Electronic supplementary material The online version of this article (doi:10.1007/s00214-016-1971-0) contains supplementary material, which is available to authorized users.

Anna Kaczmarek-Kedziera

teoadk@chem.umk.pl

1 Faculty of Chemistry, Nicolaus Copernicus University in Torun, Gagarina 7, 87-100 Toruń, Poland

\section{Introduction}

Well-ordered supramolecular assemblies are known and applied in various branches of science, technology and engineering. On the other hand, their presence can be undesirable for some applications such as in lasers or dye-sensitized solar cells. Thus, a precise control of aggregation phenomena in various solvents is of particular importance.

The aggregation is caused by relatively strong noncovalent interactions between molecules and leads to the compelling modification of their properties with respect to the isolated species. Two types of aggregates have been described depending on the observed modification of their spectra upon aggregation: $\mathrm{H}$ - and J-aggregates. For the J-aggregates, a bathochromic shift in the absorption spectrum is observed with respect to the single molecular spectrum together with a small Stokes shift and the high quantum yield for emission. On the other hand, the $\mathrm{H}$-aggregates (where $\mathrm{H}$ stands for hypsochromic) exhibit blue-shifted signals in the absorption spectrum and large Stokes shift for the weak fluorescence. This contrasting behavior of the two type of aggregates arises from different mutual orientation of transition dipole moments of their composing molecules: $\mathrm{H}$-aggregates are built of the molecules arranged face-to-face with parallel orientation of the dipoles and for the J-aggregates the displacement of the molecules is observed thus giving a "coplanar inclined" orientation of transition moments $[1,2]$.

An explanation of the shifts of the absorption bands upon aggregation has been given by Kasha et al. [1]. According to their exciton model, the shift arises due to a strong coupling between the components transition dipoles that cause an exciton splitting of the excited state. For the $\mathrm{H}$-aggregates high oscillator strength is observed at the high-energy range of the absorption band and the 
low-energy tail corresponds to forbidden transitions to the lower excitonic band edge. An opposite situation is found for the J-aggregates where the low-energy range is characterized by the large oscillator strengths, while the higher energies correspond to the forbidden transitions to the high energy level of the excitonic band.

The exciton model can be applied for the systems of the small electron overlap between the aggregate units. For the dimers of the coplanar inclined transition dipoles, the angular dependence of the exciton band splitting leads to the slip angle $\alpha$ value of $54.7^{\circ}$ as the limiting angle between the J- and H-aggregates (see Fig. 1) [3].

Squaraine dyes have attracted attention for their unique properties [4-17]. A one-dimensional molecule stacking observed in squaraine solutions is of similar nature as that recognized for cyanine or merocyanine dyes. However, the dipolar polymethine dyes are built of electron-donating and electron-accepting groups connected by an (extended) $\pi$-electron skeleton (schematically depicted as $\mathrm{D}-\pi-\mathrm{A}$ ), while the squaraine dyes consist of two donating groups attached to an accepting squaric acid moiety (represented as D-A-D). Despite of all the similarities between the molecules of these two groups, the above-mentioned differences together with their implications make squaraines still intriguing and attractive subject of research. Simple notion of bond-length alternation that allows to design polymethine dyes of desired properties such as high hyperpolarizability values fail in squaraines, where the single and double bonds exhibit various lengths. Strong intramolecular charge transfer and quadrupolar character of squaraines causes that there is still no clear definition of connections between the structure and properties for these systems.

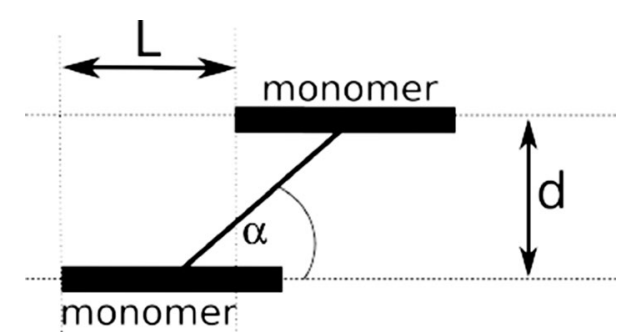

Fig. 1 A definition of the structural parameters for the aggregate: $d$ and $L$ are the displacement parameters and $\alpha$ is the slip angle
A thorough investigation of squaraines in various media has revealed that they can form either $\mathrm{H}$ - or J-aggregates depending on their structure and parameters of microenvironment $[11,18,19]$. Moreover, the given squaraine dye can be forced into the $\mathrm{H}$ - or J-aggregates by the proper choice of material preparation conditions. Additionally, the squaraines have been obtained with simultaneous coexistence of both types of aggregates in different domains [11]. In this case, the absorption band splitting is observed and the two parts appear on the spectrum: one that is bathochromically and the other-hypsochromically shifted.

A stepwise mechanism of some squaraines aggregation has been observed by Chen et al. [20] where first the dimers and later on higher aggregates were formed. Another amphiphilic squaraines have disclosed a tendency to form a stable tetrameric unit with a pinwheel structure suggested by Chen et al. [20].

From the computational point of view, squaraine dyes still are challenging and only scarce study is present in the literature mostly for single isolated molecules or simple models of dye-sensitized solar cell [14, 21-30]. Thus, the current contribution aims to carefully analyze mutual interactions in the small squaraine aggregates and their influence on the spectroscopic properties.

\section{Technical and experimental details}

\subsection{Computational methodology}

Two symmetric squaraine dyes containing nitrogen are investigated: DMASQ and DASQ (for structures and systematic name see Scheme 1). In DMASQ, nitrogen atom appears in an aniline moiety on the edge of the delocalized $\pi$-electron system, while in DASQ the nitrogen directly adjoins to a squaric ring. Geometry optimization of isolated molecules and aggregates was performed within the B97$\mathrm{D} / 6-311++\mathrm{G}(\mathrm{d}, \mathrm{p})$ approach in gas phase. Moreover, also several structures caught with the B3LYP functional are included into the investigation in order to provide for the hydrogen-bonded systems. The full optimization was performed for the aggregates containing up to four squaraine units. Due to the very complex potential energy surface, only the most prominent aggregates were investigated, since the full optimization leads to the complicated and
Scheme 1 DASQ

(2,4-bis(aminophenyl)squaraine) and DMASQ (2,4-bis(4dimethylaminophenyl)squaraine) structures
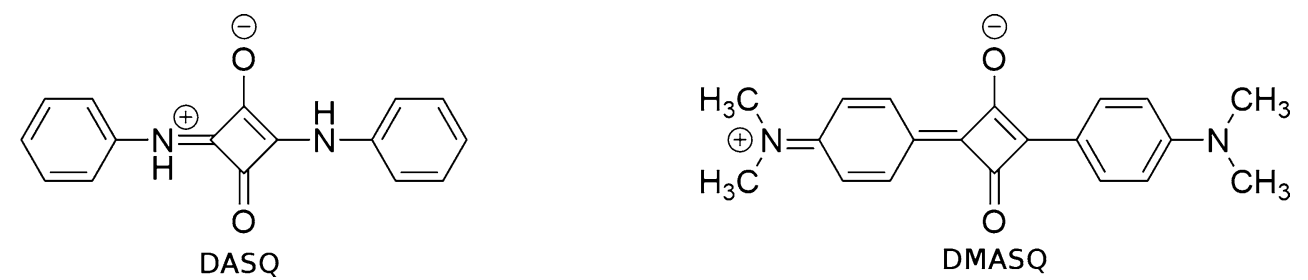
unregular aggregates. However, in order to examine also the interactions and the cooperativity in the regular aggregates, on the basis of the fully optimized structures, the frozen-geometry models up to hexamers were also included in the current study. They serve as the base for comparison of the cooperativity for the aggregates of various nature.

Supermolecular interaction energy was estimated with various functionals, namely B97 with D and D3 Grimme dispersion correction and $\omega$-B97X-D one for 6-311++

$\mathrm{G}(\mathrm{d}, \mathrm{p})$ basis set. All the above calculations have been carried out with Gaussian09 suite of programs [31]. SAPT0/cc-pVDZ interaction energy decomposition has been performed in Psi4 [32-35].

Vertical absorption spectra and corresponding contours of frontier molecular orbitals were obtained with PBE0/ccpVDZ approach in Gaussian09 [31].

\section{Results and discussions}

\subsection{Squaraine aggregates}

\subsubsection{Dimerization}

Various structures of squaraines aggregates were optimized with two functionals, namely B97-D including Grimme dispersion correction and B3LYP (conventional hybrid functional with no additional dispersion taken into account).

The dimers of the two analyzed squaraine dyes are presented in Figs. 2 and 3. In agreement with the chemical intuition, the optimized structure of dimers for DMASQ and DASQ differs, since the latter can form effective hydrogen bonds between monomers and the former lacks a strong hydrogen donor. The H-bond pattern in the DASQ dimer that contains two strong O...H-N bonds is highly stabilizing and even within the B97-D functional the almost planar dimer (f) occurs as most stable. This is in opposition to the case of the DMASQ molecule, where only weak $\mathrm{O} \ldots \mathrm{H}-\mathrm{C} \mathrm{H}-$ bonds can be formed and they do not prevail the dispersion interaction. Thus, for DMASQ, B97-D leads only to sandwich structures and $\mathrm{H}$-bonds can be observed only in fictitious B3LYP-optimized dimers (structure (a)).

Table 1 presents the supermolecular interaction energy for the dimers depicted in Figs. 2 and 3. For the comparison, the density functional data were juxtaposed with the MP2 results. However, even on the first sight, the MP2 calculations seem to be of poor quality giving - as could be expected [36, 37]—-large value of the basis set superposition error (BSSE). Taking into account the medium-sized basis set such as $6-311++\mathrm{G}(\mathrm{d}, \mathrm{p})$, and the BSSE value for MP2 varies from 20 to 30 to even more than $100 \%$ of the interaction energy values. This disqualifies this method for the further investigation. The applied DFT functionals give a qualitative agreement, and their results unequivocally show the favorable dimers structures as DMASQ(c) and DASQ(f).

\subsubsection{Higher aggregates}

Careful analysis of the higher squaraine aggregatestrimers and tetramers-leads to the observation of some
Fig. 2 DMASQ dimers a optimized within the B3LYP approach and $\mathbf{b}, \mathbf{c}$ optimized within the B97-D approach. Here and later on dashed lines and small numbers in the structures denote chosen distances (in $\AA$ ) and below the supermolecular B97-D interaction energy is given in $(\mathrm{kcal} / \mathrm{mol})$ (a)

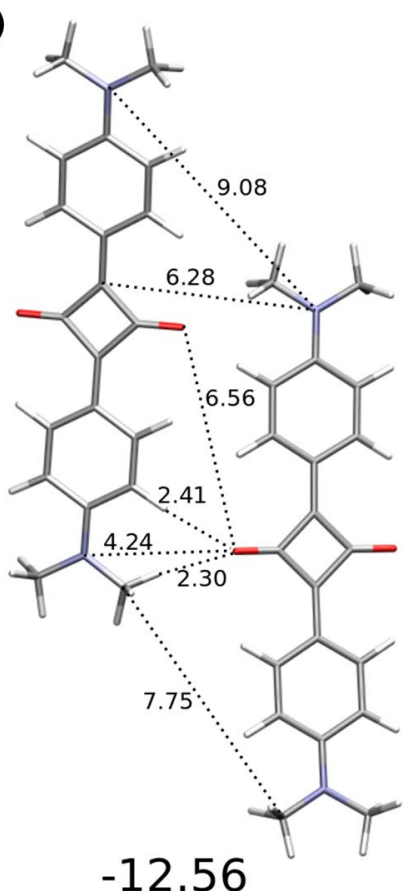

(b)

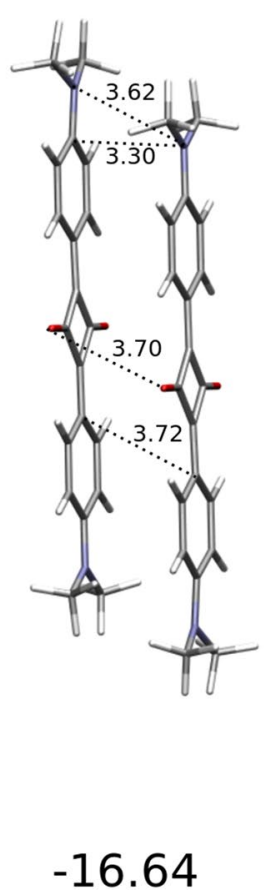

(c)

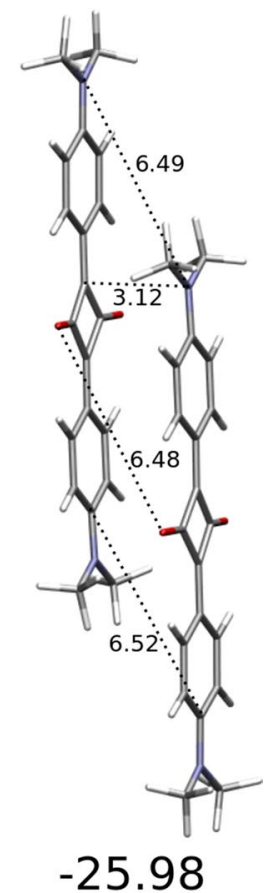


(a)

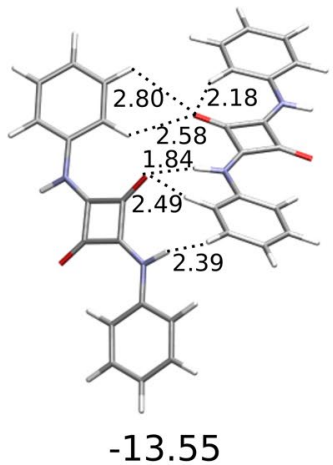

(c)

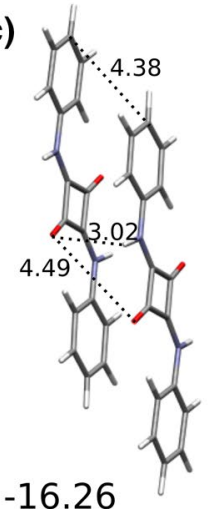

(d)

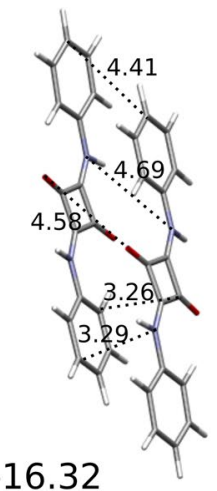

(b)

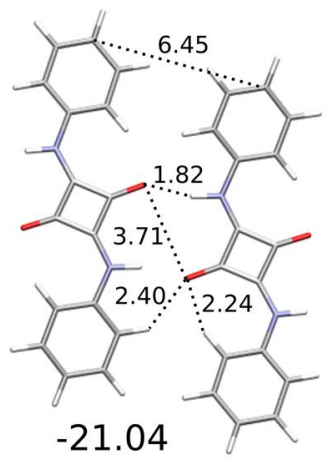

(e)

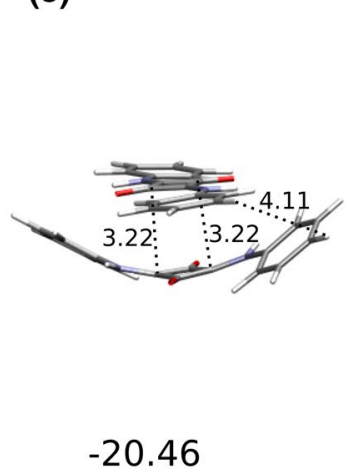

(f)

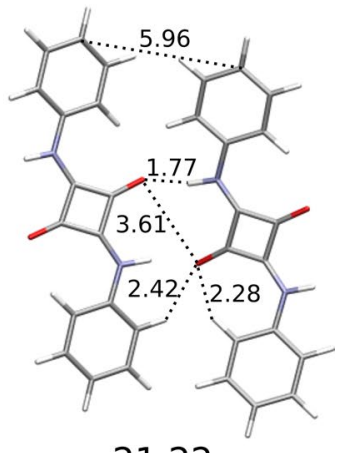

$-21.22$

Fig. 3 DASQ dimers a-b optimized with the B3LYP approach and $\mathbf{c}-\mathbf{f}$ optimized within the B97-D approach

Table 1 Counterpoisecorrected interaction energy and basis set superposition error (all in $[\mathrm{kcal} / \mathrm{mol}]$ ) calculated within various approaches for 6-311++G(d,p) basis set of squaraine dimers presented in Figs. 2 and 3

\begin{tabular}{|c|c|c|c|c|c|c|c|c|}
\hline \multirow[t]{2}{*}{ Approach } & \multicolumn{4}{|c|}{ Interaction energy } & \multicolumn{4}{|l|}{ BSSE } \\
\hline & B97-D & B97-D3 & $\omega \mathrm{B} 97-\mathrm{xD}$ & MP2 & B97-D & B97-D3 & $\omega \mathrm{B} 97-\mathrm{xD}$ & MP2 \\
\hline DMASQ(a) & -12.56 & -12.79 & -13.08 & -12.23 & 0.75 & 0.75 & 0.85 & 4.66 \\
\hline DMASQ(b) & -16.64 & -17.43 & -19.08 & -20.85 & 4.14 & 4.14 & 4.49 & 23.67 \\
\hline DMASQ(c) & -25.98 & -25.82 & -27.05 & -28.18 & 3.46 & 3.46 & 3.86 & 21.38 \\
\hline DASQ(a) & -13.55 & -14.03 & -15.06 & -13.54 & 1.21 & 1.21 & 1.32 & 6.14 \\
\hline DASQ(b) & -21.04 & -22.08 & -24.21 & -21.58 & 1.18 & 1.18 & 1.26 & 5.78 \\
\hline DASQ(c) & -16.26 & -17.89 & -18.19 & -19.69 & 3.26 & 3.26 & 3.54 & 18.48 \\
\hline $\operatorname{DASQ}(\mathrm{d})$ & -16.32 & -17.91 & -18.37 & -19.81 & 3.30 & 3.30 & 3.53 & 18.12 \\
\hline DASQ(e) & -20.46 & -21.04 & -21.75 & -23.16 & 3.22 & 3.22 & 3.46 & 19.48 \\
\hline DASQ(f) & -21.22 & -22.07 & -24.48 & -21.15 & 1.40 & 1.40 & 1.55 & 7.33 \\
\hline
\end{tabular}

regularities (Tables 2, 3). As could be easily expected, for DMASQ molecule that does not possess the H-bond donating moieties, the $\mathrm{H}$-bonded patterns do not occur readily. The obtained H-bonded structures are artificially caught in minima by using the B3LYP functional with no dispersion correction. The dispersion-corrected density functional theory always generates sandwich-like displaced structures with no H-bonds. On the other hand, for DASQ squaraine, where both proton-accepting and proton-donating moieties are present in the molecule, the H-bonded structures appear with any applied functional, also without the dispersion correction. Taking into account the sequence of dimers, trimers and tetramers for DMASQ and DASQ, the series of different interaction nature can be observed due to the structural differences of both systems. The most stable structures for DMASQ oligomers can be characterized as parallel displaced with the clenched endings. This clenching forms a closed system in which the two molecules confine the third one between them (see trimer (b) or tetramer (e)). Such a clenching in a zig-zag mode requires the relatively large mutual displacement of the molecules of about $5.5 \AA$-the squaric acid ring interacts with the $\mathrm{C}-\mathrm{N}$ bond of the adjacent system. The interaction energy obtained for these clenched oligomers is equal to $-25.98,-51.53$ and 
Table 2 Counterpoisecorrected interaction energy and basis set superposition error (all in $[\mathrm{kcal} / \mathrm{mol}]$ ) calculated within various approaches for $6-311++\mathrm{G}(\mathrm{d}, \mathrm{p})$ basis set of squaraine trimers presented in Figs. 4 and 5
Table 3 Counterpoisecorrected interaction energy and basis set superposition error (all in $[\mathrm{kcal} / \mathrm{mol}]$ ) calculated within various approaches for 6-311++G(d,p) basis set of squaraine tetramers presented in Figs. 6 and 7

\begin{tabular}{|c|c|c|c|c|c|c|}
\hline \multirow[t]{2}{*}{ Approach } & \multicolumn{3}{|c|}{ Interaction energy } & \multicolumn{3}{|l|}{ BSSE } \\
\hline & B97-D & B97-D3 & $\omega \mathrm{B} 97-\mathrm{xD}$ & B97-D & B97-D3 & B97-xD \\
\hline DMASQ(a) & -24.79 & -25.19 & -25.80 & 1.55 & 1.55 & 1.76 \\
\hline DMASQ(b) & -51.53 & -50.37 & -53.68 & 8.31 & 8.31 & 8.65 \\
\hline DMASQ(c) & -34.48 & -35.53 & -38.45 & 8.42 & 8.42 & 9.26 \\
\hline DMASQ(d) & -32.29 & -33.31 & -36.19 & 8.92 & 8.92 & 9.45 \\
\hline $\operatorname{DASQ}(a)$ & -31.30 & -32.58 & -34.83 & 3.30 & 3.30 & 3.59 \\
\hline DASQ(b) & -26.16 & -27.07 & -29.11 & 2.29 & 2.29 & 2.50 \\
\hline $\operatorname{DASQ}(\mathrm{c})$ & -27.94 & -29.11 & -30.73 & 2.79 & 2.79 & 3.08 \\
\hline $\operatorname{DASQ}(\mathrm{d})$ & -27.82 & -29.31 & -30.99 & 3.23 & 3.23 & 3.53 \\
\hline DASQ(e) & -29.81 & -31.28 & -33.01 & 3.17 & 3.17 & 3.53 \\
\hline DASQ(f) & -41.23 & -43.21 & -47.06 & 2.41 & 2.41 & 2.62 \\
\hline DASQ(g) & -40.10 & -41.52 & -42.45 & 6.74 & 6.74 & 7.21 \\
\hline DASQ(h) & -34.10 & -36.77 & -37.73 & 6.75 & 6.75 & 7.15 \\
\hline DASQ(i) & -34.11 & -36.78 & -37.74 & 6.75 & 6.75 & 7.15 \\
\hline DASQ(j) & -32.50 & -35.20 & -35.97 & 6.58 & 6.58 & 6.93 \\
\hline DASQ(k) & -40.94 & -42.60 & -45.85 & 4.50 & 4.50 & 4.84 \\
\hline
\end{tabular}

\begin{tabular}{llllrrrr}
\hline Approach & \multicolumn{2}{l}{ Interaction energy } & & \multicolumn{2}{l}{ BSSE } & & \\
\cline { 2 - 3 } & B97-D & B97-D3 & $\omega$ B97-xD & & B97-D & B97-D3 & B97-xD \\
\hline DMASQ(a) & -49.91 & -39.35 & -56.88 & & 12.86 & 12.86 & 13.70 \\
DMASQ(b) & -15.50 & -17.67 & -17.39 & & 4.54 & 4.54 & 4.90 \\
DMASQ(c) & -37.04 & -37.57 & -38.52 & & 2.32 & 2.33 & 2.64 \\
DMASQ(d) & -52.70 & -54.02 & -58.07 & & 13.12 & 13.14 & 14.19 \\
DMASQ(e) & -79.07 & -77.87 & -82.64 & & 11.99 & 11.99 & 12.73 \\
DMASQ(f) & -41.00 & -41.82 & -48.19 & & 10.45 & 10.45 & 11.03 \\
DMASQ(g) & -70.77 & -70.33 & -76.11 & & 10.73 & 10.48 & 11.38 \\
DASQ(a) & -40.22 & -41.58 & -44.42 & & 3.63 & 3.63 & 3.88 \\
DASQ(b) & -40.09 & -41.67 & -44.10 & & 3.84 & 3.84 & 4.24 \\
DASQ(c) & -41.30 & -49.13 & -45.84 & & 3.65 & 10.37 & 4.00 \\
DASQ(d) & -62.07 & -65.09 & -70.78 & & 3.65 & 3.65 & 3.86 \\
DASQ(e) & -56.20 & -58.45 & -59.47 & & 10.67 & 10.67 & 11.35 \\
DASQ(f) & -50.94 & -54.74 & -55.87 & & 10.10 & 10.32 & 10.92 \\
DASQ(g) & -49.13 & -52.92 & -53.76 & & 10.37 & 10.37 & 10.97 \\
DASQ(h) & -63.04 & -65.49 & -71.56 & 4.47 & 4.47 & 4.98 \\
\hline
\end{tabular}

$-79.07 \mathrm{kcal} / \mathrm{mol}$, respectively, in the case of the dimer, trimer and tetramer in B97-D approach. The smaller displacement of about $2 \AA$ leads to the zig-zag oligomers characterized by the smaller interaction energies: -16.64 , -32.29 and $-49.91 \mathrm{kcal} / \mathrm{mol}$, respectively for dimer, trimer and tetramer. On the other hand, the arrangement with a small displacement not in a zig-zag, but in a staircase mode ( $\mathrm{S}$ sequence), leads to the sequence of the interaction energies $-16.64,-34.48$ and $-52.70 \mathrm{kcal} / \mathrm{mol}$ in a dimer, trimer and tetramer, respectively.

For DASQ oligomers also three sequences can be considered. First, the most stable H-bonded structure with the interaction energies of -21.04 (or -21.22 ), -41.23 and -62.03 (or -63.04) $\mathrm{kcal} / \mathrm{mol}$, respectively, for the dimer (b) (or (f)), trimer (f) and tetramer (d) (or (h)). The next one could be called staircase-like and would be formed by the dimer (c) or (d), trimer (h) or (j) and tetramer (f) giving, respectively, the interaction energies of -16.26 (or -16.32), -34.10 (or -34.11) and $-50.94 \mathrm{kcal} / \mathrm{mol}$. The third series is built in the zig-zag mode and consists of the dimer (c) or (d) (interaction energy of -16.26 or $-16.32 \mathrm{kcal} / \mathrm{mol}$, respectively), trimer (j) (interaction energy of $-32.50 \mathrm{kcal} / \mathrm{mol}$ ) and tetramer $(\mathrm{g})$ (interaction energy equal to $-49.13 \mathrm{kcal} / \mathrm{mol}$ ). 
(a)

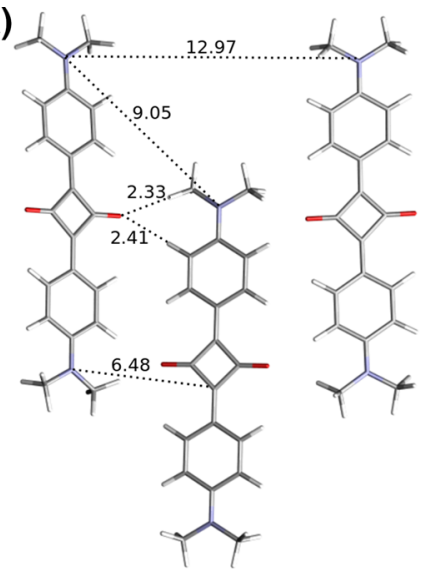

$-24.79$ (b)

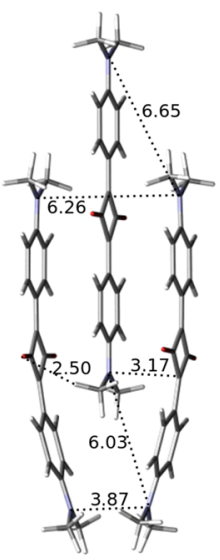

$-51.53$ (c)

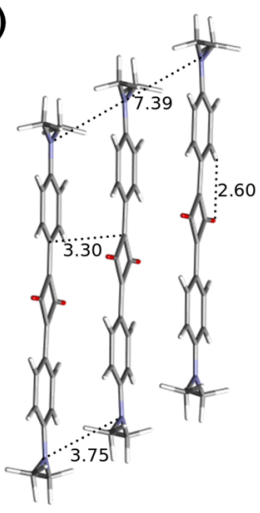

$-34.48$ (d)

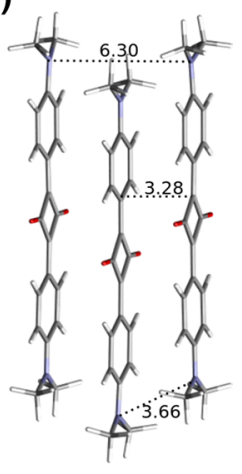

$-32.29$

Fig. 4 DMASQ trimers a optimized within the B3LYP approach and b-d optimized within the B97-D approach

(a)

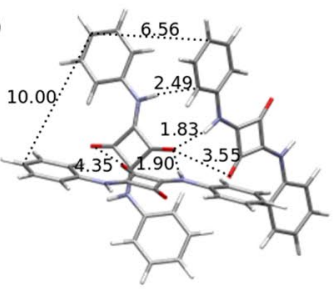

$-31.30$ (b)

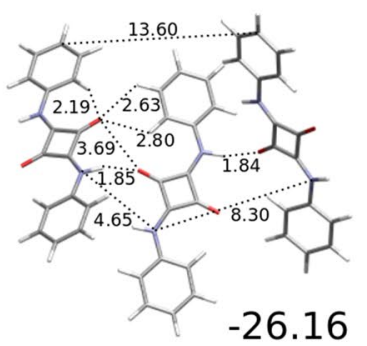

(c)

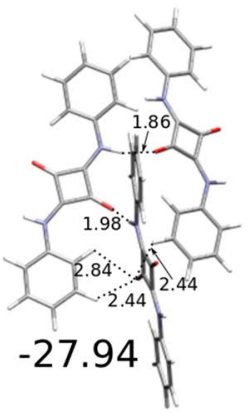

(d)

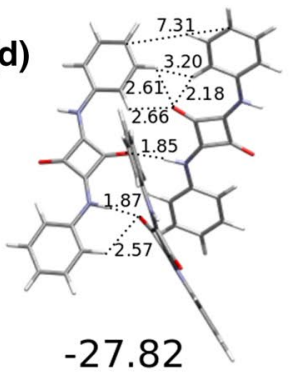

(e)
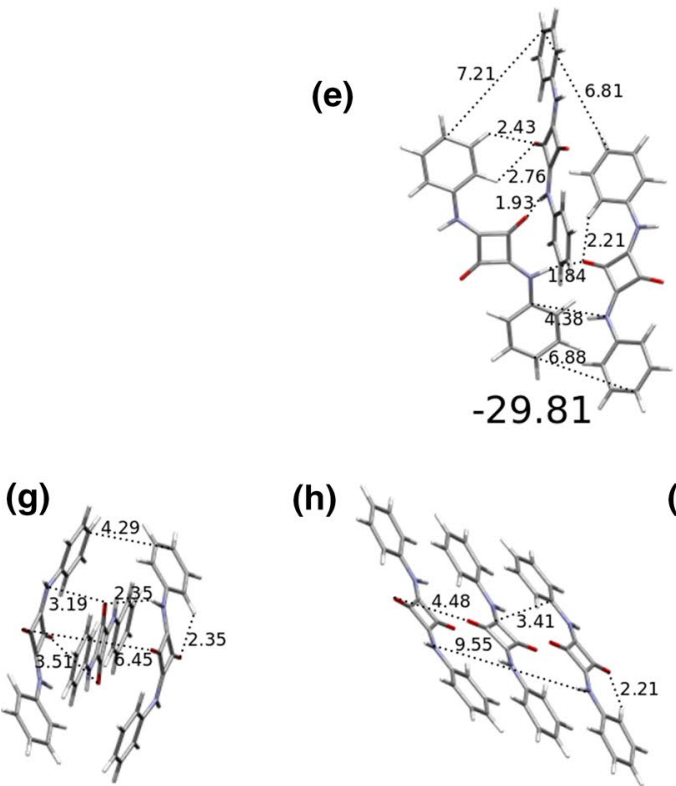

$-40.10$ (h)

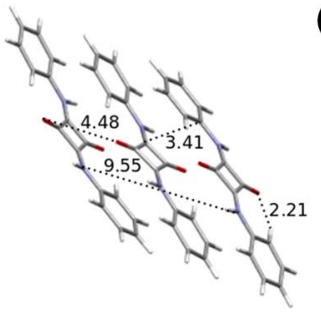

$-34.10$ (i)

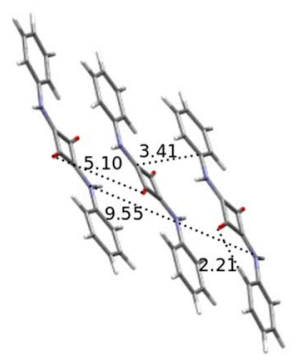

$-34.11$

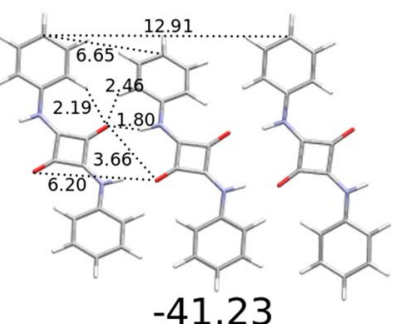

$-41.23$

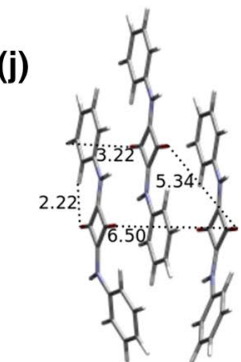

$-32.50$ (k)

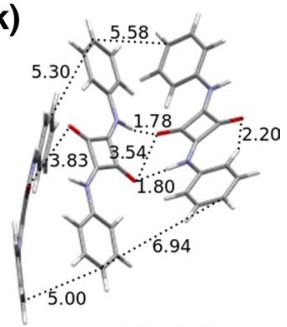

$-40.94$

Fig. 5 DASQ trimers a-f optimized within the B3LYP approach and $\mathbf{g}-\mathbf{k}$ optimized within the B97-D approach

For clear and systematic investigation of the aggregation phenomena in the further part of this study, only the above-mentioned sequences will be discussed.
They were also extended to the higher oligomers (pentamers and hexamers) in order to analyze the general tendencies. 
(a)

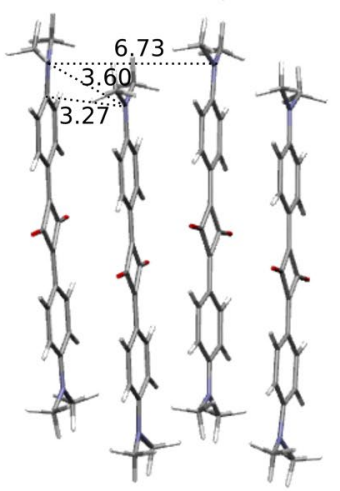

$-54.31$

(d)

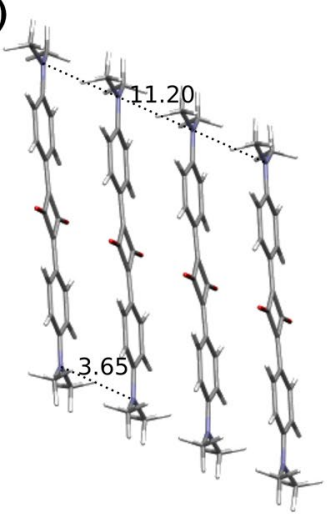

$-52.70$ (b)

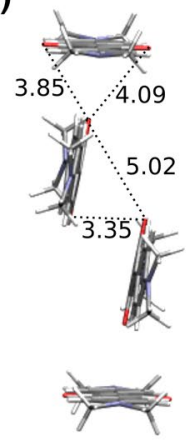

$-15.50$

(e)
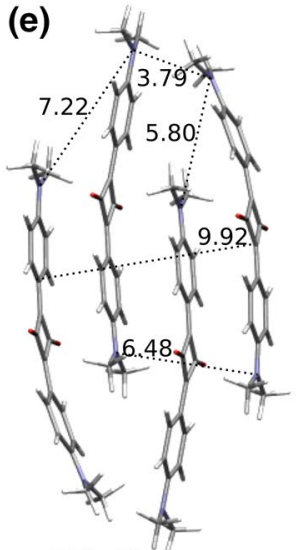

$-79.07$ (c)

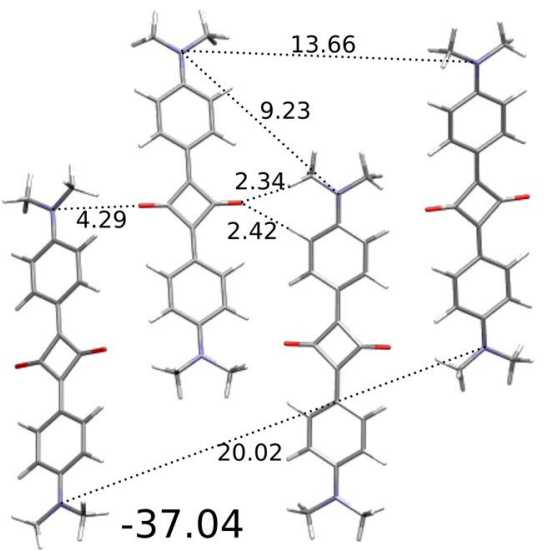

(f)

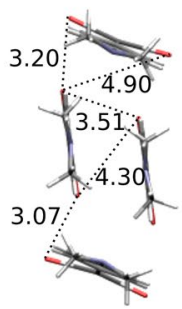

$-41.00$ (g)

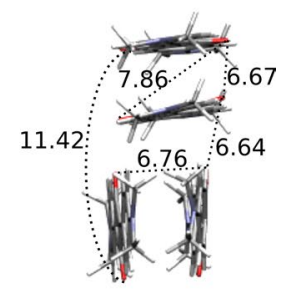

$-70.77$

Fig. 6 DMASQ tetramers a-c optimized within the B3LYP approach and $\mathbf{d}-\mathbf{g}$ optimized within the B97-D approach

\subsection{Frozen squaraine oligomers}

Due to the regular and ordered structure of the reported squaraine aggregates, the "one-dimensional" oligomers with fixed (frozen) geometry were investigated. Five various structures for the DMASQ oligomers were investigated on the basis of the full geometry optimizations up to tetramers: H-bonded one (further denoted as $\mathrm{Hb}$ ), two stacked of the staircase type with two different monomer shifts: 3 (s3) and 6 (s6) $\AA$ and similarly two stacked of the zig-zag type with two shifts: 3 (z3) and 6 (z6) A.. Moreover, for the DASQ system, three non-relaxed oligomer types were analyzed: H-bonded staircase-like (Hb-s), stacked staircase (s) and stacked zig-zag (z). Their structures are depicted in Figs. 8 and 9.

Figure 10 and Table 4 summarize the interaction energies for the investigated oligomers up to hexamer. Left panels of Fig. 10 present the change of a total supermolecular interaction energy with chain elongation for DMASQ and DASQ, respectively, and right panels - the interaction energy per contact. Collected data suggest that the DASQ molecules behave in principle similarly for each oligomer type, and the interaction energy per contact remains constant with the chain elongation in the range from -16.4 to $-19.94 \mathrm{kcal} /$ mol. The situation slightly differs for DMASQ, where the interaction energy per contact significantly depends on the system type. Namely, for the hydrogen-bonded oligomers, the interaction energy per contact is the smallest and lies in the range from -10.28 to $-6.02 \mathrm{kcal} / \mathrm{mol}$, while for the remaining oligomers this energy is larger than $15 \mathrm{kcal} / \mathrm{mol}$ (and the largest for the s6 system: from $-23.79 \mathrm{kcal} / \mathrm{mol}$ for the dimer to $-25.14 \mathrm{kcal} / \mathrm{mol}$ for the hexamer). DMASQ $\mathrm{s} 3$, z3 and z6 complexes give practically identical results and their curves in Fig. 10 in principle lineup. This seems selfevident at least for $\mathrm{s} 3$ and $\mathrm{z} 3$ oligomers while analyzing the molecule placement in the chain: In both the staircase and zig-zag mode, the interaction is dominated by the interactions between the aromatic rings lying closely to each other. 
(a)

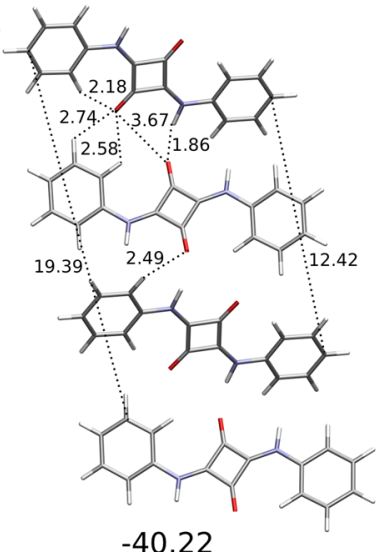

(b)

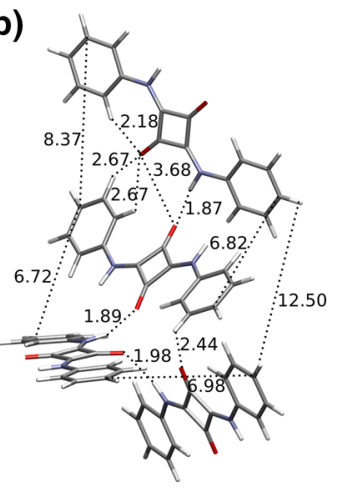

$-40.09$

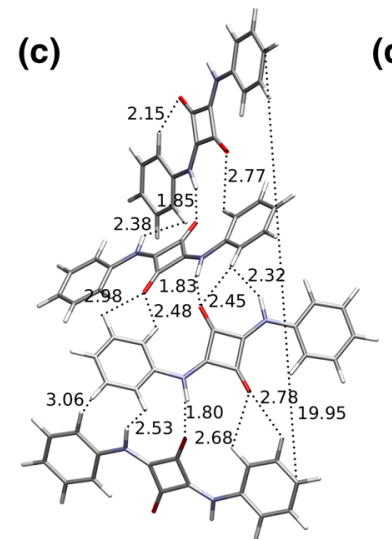

$-41.30$ (d)

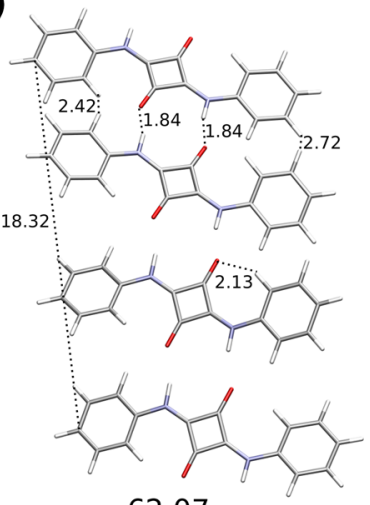

$-62.07$ (e)

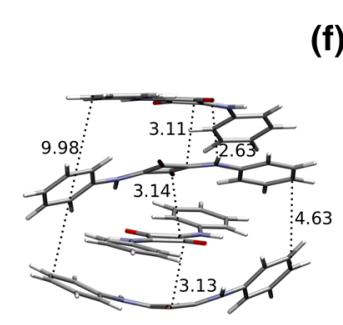

$-56.20$ (f)

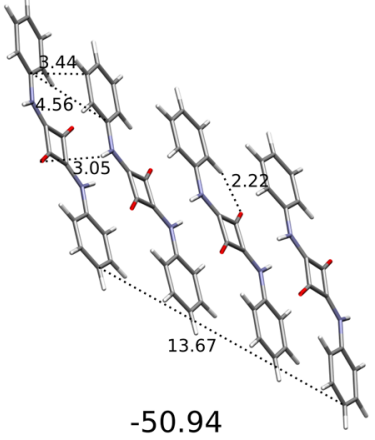

(g)

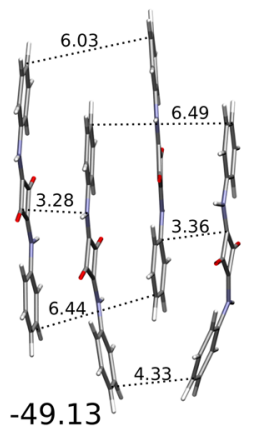

(h)

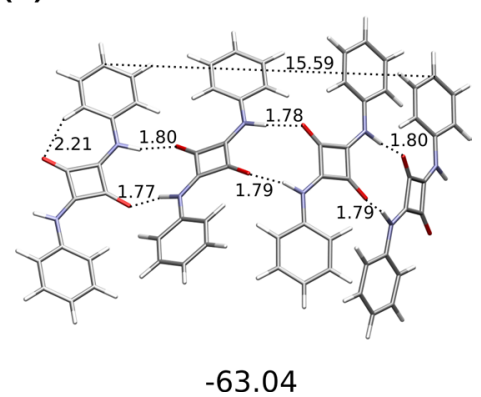

Fig. 7 DASQ tetramery a-d optimized within the B3LYP approach and $\mathbf{e}-\mathbf{h}$ optimized within the B97-D approach
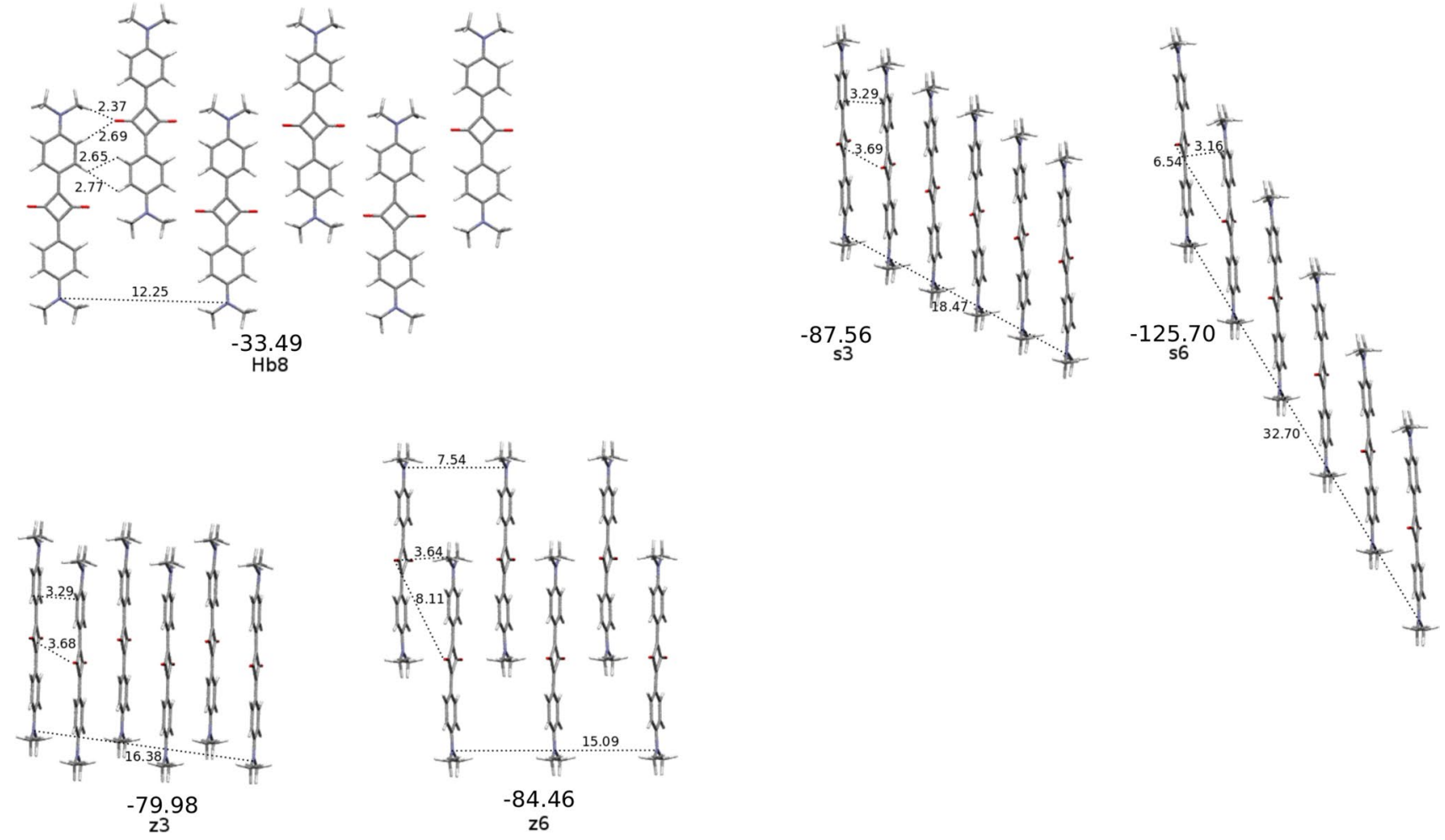

Fig. 8 Fixed-geometry DMASQ oligomers 
Fig. 9 Fixed-geometry DASQ oligomers

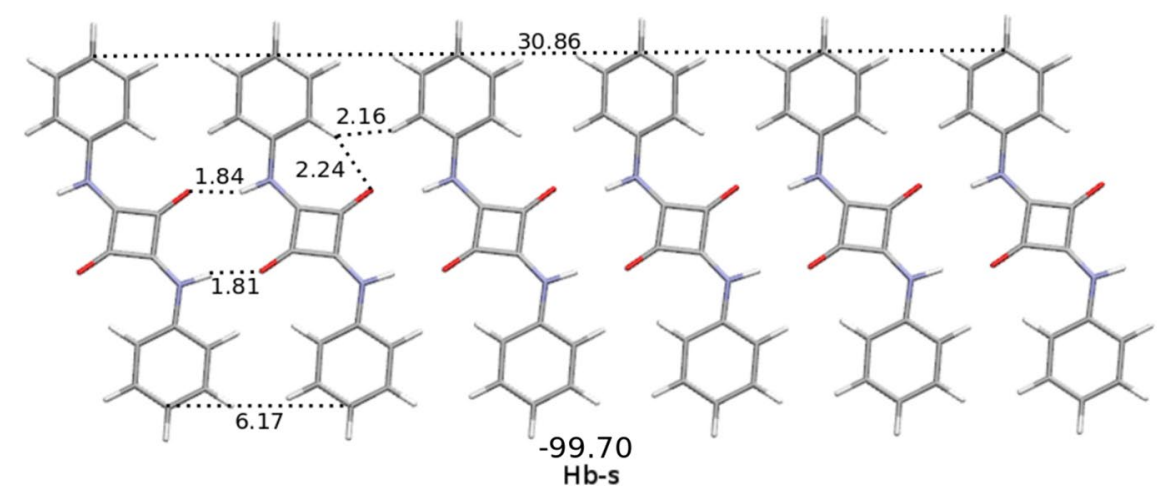

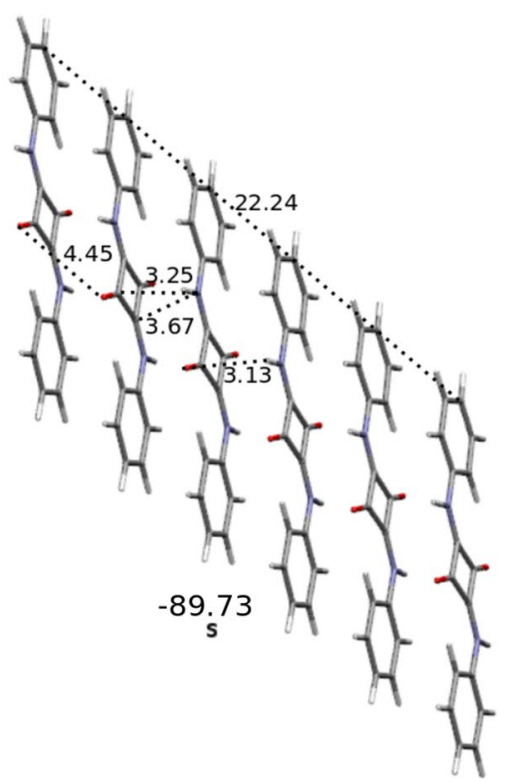

$-85.25$
Fig. 10 Interaction energy with respect to the chain size for the frozen-geometry oligomers of DMASQ (upper panel) and DASQ (lower panel) and their corresponding interaction energy per contact (all data in $\mathrm{kcal} / \mathrm{mol}$ )
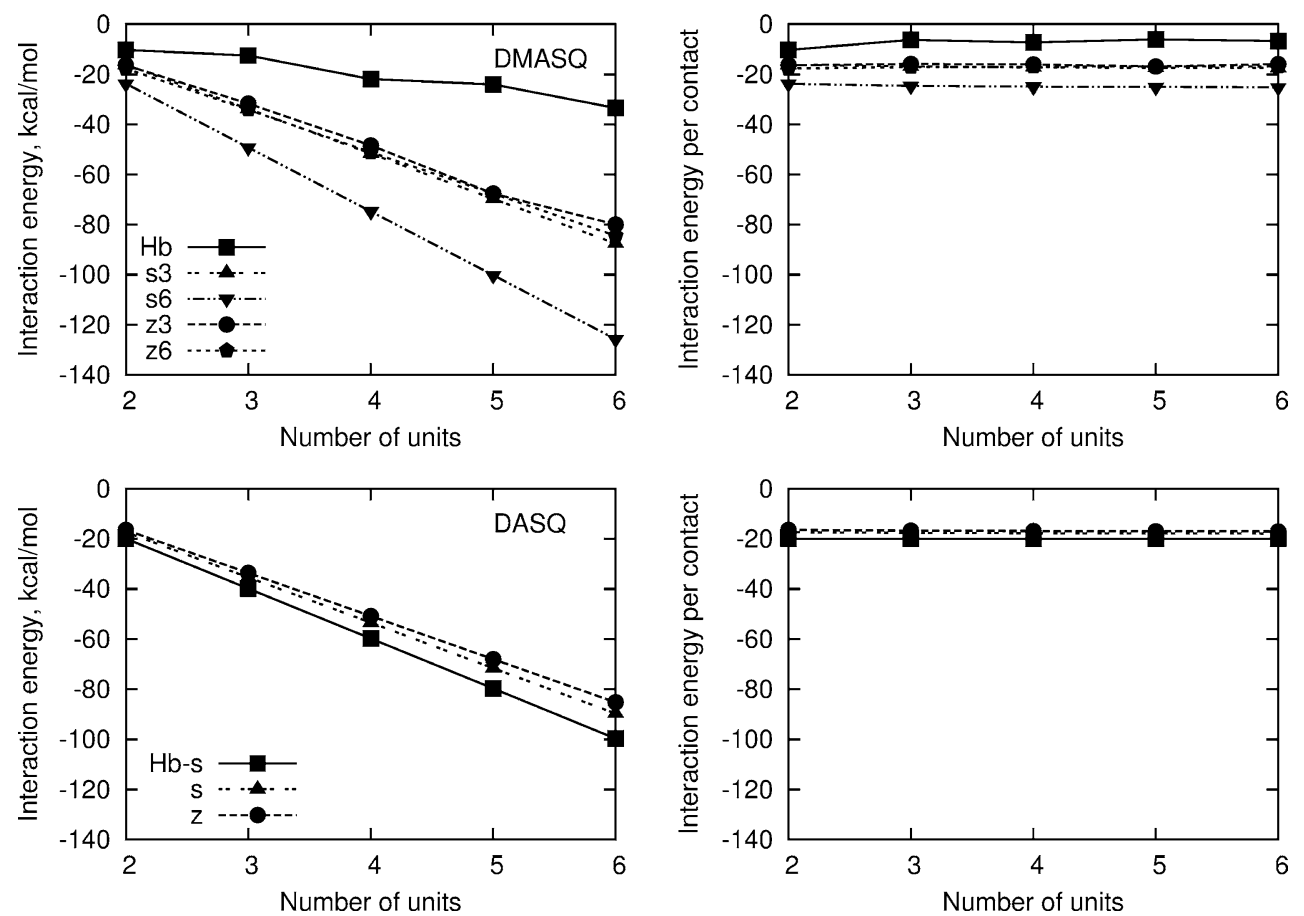
Fig. 11 SAPT0 interaction energy components (electrostatic and dispersion) for DMASQ and DASQ fully optimized dimers and the corresponding disp./elst. ratio
Fig. 12 SAPT0 interaction energy components (electrostatic and dispersion) for DMASQ and DASQ frozen dimers and the corresponding disp./elst. ratio

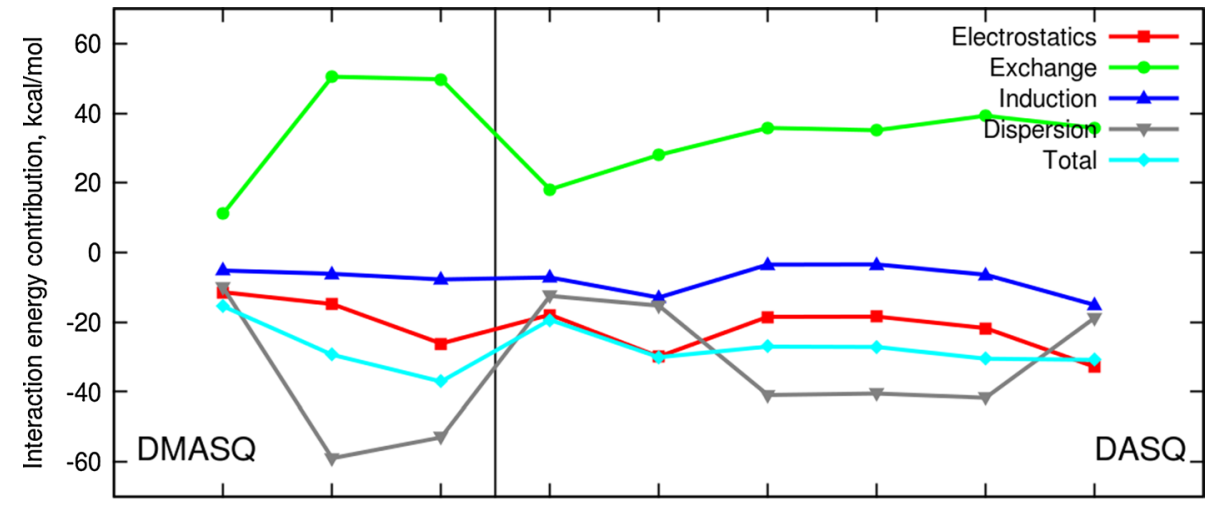

(a)

(b) (c)

(a)

(b)

(c)

(d)

(e) (f)
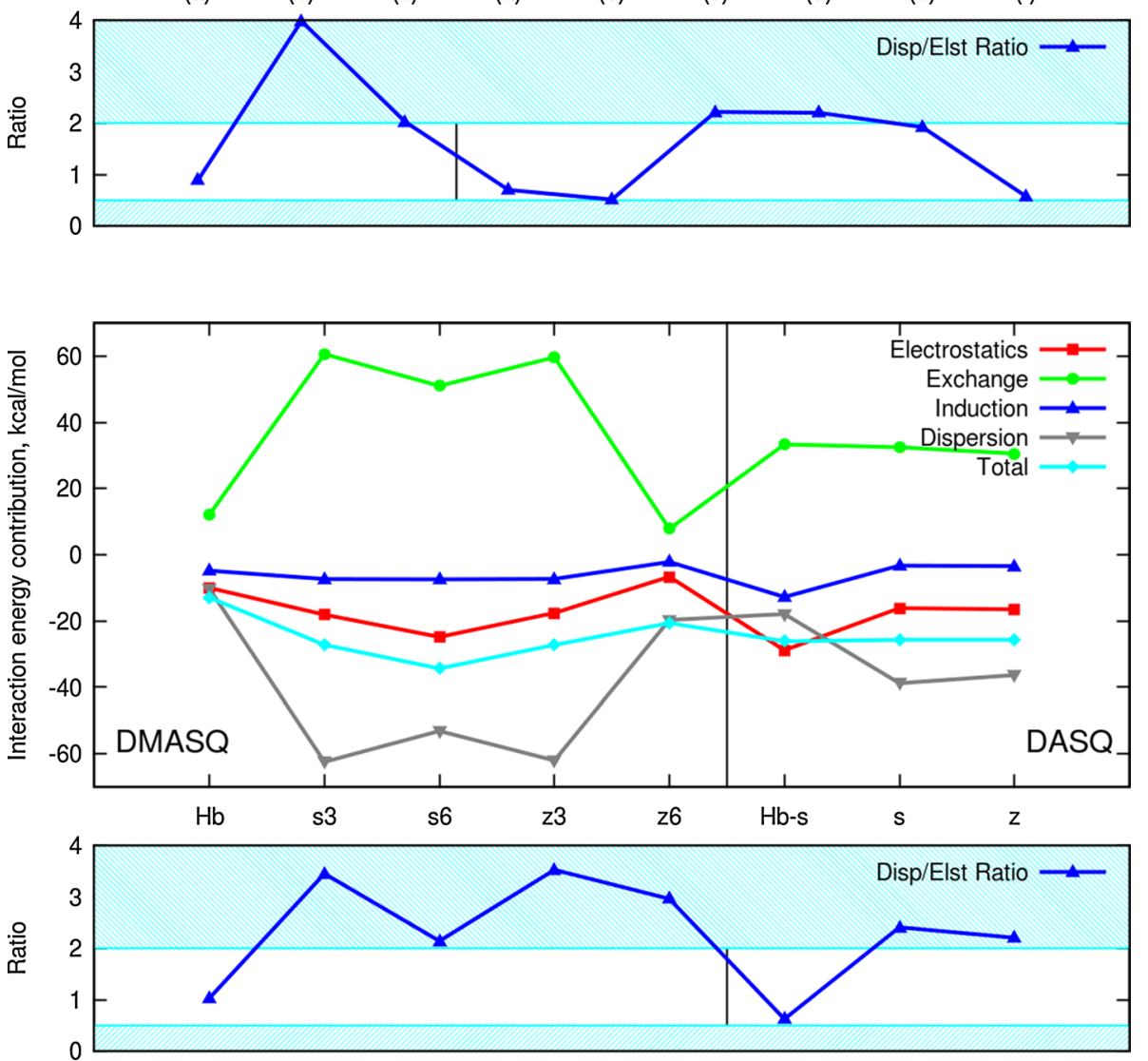

\section{A nature of DMASQ and DASQ interaction in dimers}

Summary of the interaction energy components for both fully optimized and fixed frozen DMASQ and DASQ dimers is presented in Tables 5 and 6 and in Figs. 11 and 12. As could be expected, the full optimization of the dimers leads to the strongest total interaction between molecules. Taking into account the ratio of dispersion to electrostatic contribution, which allows to classify the dimers as dispersion-bound (ratio larger than 2) or electrostaticbound (ratio smaller than 0.5 ), one can observe that most of the analyzed dimers of both classes (optimized and frozen) posses the dispersion character. Clear domination of the electrostatic component can be noticed only for DASQ dimers (since DMASQ does not contain the labile protons connected to the electronegative atoms). However, it is still not significant enough to classify the (b) and (f) DASQ dimers as clearly electrostatic (dispersion to electrostatic ratio, respectively, 0.51 and 0.57 ). A comparison of the DMASQ and DASQ dimers leads to the conclusion that while the electrostatic contributions seem to be more pronounced for DASQ, the dispersion interaction predominates significantly in the case of DMASQ. The most stable dimer with the total SAPT0 interaction energy equal to $-37.02 \mathrm{kcal} / \mathrm{mol}$ is depicted in Fig. 2(panel (c)) and has the 
Table 4 Counterpoise-corrected interaction energy and counterpoise-corrected interaction energy per contact calculated within $\omega$ B97X-D/juncc-pVTZ approach for squaraine DMASQ chains with no relaxation

\begin{tabular}{|c|c|c|c|c|c|c|c|c|c|c|c|}
\hline \multirow{2}{*}{$\begin{array}{l}\text { Oligomer } \\
\text { DMASQ }\end{array}$} & \multirow[t]{2}{*}{ NBas } & \multicolumn{2}{|l|}{$\mathrm{Hb}$} & \multicolumn{2}{|l|}{ s3 } & \multicolumn{2}{|l|}{ s6 } & \multicolumn{2}{|l|}{ z3 } & \multicolumn{2}{|l|}{ z6 } \\
\hline & & $E_{\text {int }}$ & $\frac{E_{\text {int }}}{\text { contact }}$ & $E_{\text {int }}$ & $\frac{E_{\text {int }}}{\text { contact }}$ & $E_{\text {int }}$ & $\frac{E_{\text {int }}}{\text { contact }}$ & $E_{\text {int }}$ & $\frac{E_{\text {int }}}{\text { contact }}$ & $E_{\text {int }}$ & $\frac{E_{\text {int }}}{\text { contact }}$ \\
\hline \multicolumn{12}{|c|}{ jun-cc-pVTZ } \\
\hline Dimer & 2432 & -10.31 & -10.31 & -15.64 & -15.64 & -23.12 & -23.12 & -15.79 & -15.79 & -17.37 & -17.37 \\
\hline Trimer & 3648 & -12.31 & -6.16 & -32.65 & -16.32 & -47.85 & -23.92 & -30.52 & -15.26 & -33.42 & -16.71 \\
\hline $\begin{array}{c}\text { Tetramer } \\
\text { aug-cc-pVD }\end{array}$ & \multicolumn{10}{|c|}{ aug-cc-pVDZ } & -16.68 \\
\hline Dimer & 1464 & -10.28 & -10.28 & -16.25 & -16.25 & -23.79 & -23.79 & -16.41 & -16.41 & -17.71 & -17.71 \\
\hline Trimer & 2196 & -12.49 & -6.24 & -33.85 & -16.92 & -49.21 & -24.60 & -31.74 & -15.87 & -34.16 & -17.08 \\
\hline Tetramer & 2928 & -21.93 & -7.31 & -51.68 & -17.23 & -74.72 & -24.91 & -48.38 & -16.13 & -51.10 & -17.03 \\
\hline Pentamer & 3660 & -24.07 & -6.02 & -69.74 & -17.44 & -100.22 & -25.06 & -63.48 & -15.87 & -67.62 & -16.90 \\
\hline Hexamer & 4392 & -33.49 & -6.70 & -87.56 & -17.51 & -125.70 & -25.14 & -79.98 & -16.00 & -84.46 & -16.89 \\
\hline Oligomer & NBas & \multicolumn{2}{|l|}{$\mathrm{Hbs}$} & \multicolumn{3}{|c|}{$\mathrm{s}$} & \multicolumn{5}{|c|}{$\mathrm{z}$} \\
\hline DASQ & & $E_{\text {int }}$ & & & & $\frac{E_{\text {int }}}{\text { contact }}$ & $E_{\mathrm{int}}$ & $\frac{E_{\text {int }}}{\text { contact }}$ & & & \\
\hline \multicolumn{12}{|c|}{ aug-cc-pVDZ } \\
\hline Dimer & 1136 & -19.92 & & & 7.36 & -17.36 & -16.48 & -16.48 & & & \\
\hline Trimer & 1704 & -39.84 & & & 5.36 & -17.68 & -33.60 & -16.80 & & & \\
\hline Tetramer & 2272 & -59.78 & & & 3.47 & -17.82 & -50.82 & -16.94 & & & \\
\hline Pentamer & 2840 & -79.74 & & & 1.60 & -17.90 & -68.02 & -17.00 & & & \\
\hline Hexamer & 3408 & -99.70 & & & 9.73 & -17.95 & -85.25 & -17.05 & & & \\
\hline
\end{tabular}

Table 5 SAPT0/aug-ccpVDZ interaction energy decomposition for fully optimized DMASQ and DASQ dimers (in $\mathrm{kcal} / \mathrm{mol}$ )

\begin{tabular}{|c|c|c|c|c|c|c|c|c|c|}
\hline \multirow[t]{2}{*}{ Component } & \multicolumn{3}{|l|}{ DMASQ } & \multicolumn{6}{|l|}{ DASQ } \\
\hline & (a) & (b) & (c) & (a) & (b) & (c) & (d) & (e) & (f) \\
\hline Electrostatics & -11.39 & -14.79 & -26.12 & -17.85 & -29.89 & -18.44 & -18.38 & -21.70 & -32.77 \\
\hline $\mathrm{E}_{\mathrm{elst}, r}^{(10)}$ & -11.39 & -14.79 & -26.12 & -17.85 & -29.89 & -18.44 & -18.38 & -21.70 & -32.77 \\
\hline Exchange & 11.22 & 50.50 & 49.77 & 18.11 & 28.02 & 35.78 & 35.12 & 39.27 & 35.77 \\
\hline $\mathrm{E}_{\text {exch }}^{(10)}$ & 11.22 & 50.50 & 49.77 & 18.11 & 28.02 & 35.78 & 35.12 & 39.27 & 35.77 \\
\hline $\mathrm{E}_{\mathrm{exch}}^{(10)}\left(\mathrm{S}^{2}\right)$ & 11.19 & 50.40 & 49.72 & 17.97 & 27.79 & 35.67 & 35.03 & 39.19 & 35.44 \\
\hline Induction & -5.15 & -6.10 & -7.71 & -7.14 & -12.91 & -3.46 & -3.41 & -6.36 & -15.02 \\
\hline $\mathrm{E}_{\text {ind }, r}^{(20)}$ & -5.23 & -21.57 & -21.90 & -9.06 & -13.40 & -18.08 & -17.93 & -18.48 & -16.52 \\
\hline $\mathrm{E}_{\text {exch-ind }, r}^{(20)}$ & 1.88 & 19.42 & 18.91 & 4.70 & 5.93 & 16.66 & 16.52 & 14.90 & 8.22 \\
\hline$\delta_{r}^{\mathrm{HF}}(2)$ & -1.80 & -3.95 & -4.72 & -2.78 & -5.43 & -2.04 & -1.99 & -2.78 & -6.73 \\
\hline Dispersion & -10.11 & -58.94 & -52.96 & -12.45 & -15.25 & -40.88 & -40.45 & -41.68 & -18.77 \\
\hline $\mathrm{E}_{\mathrm{disp}}^{(20)}$ & -11.21 & -66.90 & -60.45 & -14.04 & -17.38 & -46.59 & -46.08 & -47.10 & -21.56 \\
\hline $\mathrm{E}_{\mathrm{exch}-\text { disp }}^{(20)}$ & 1.10 & 7.96 & 7.49 & 1.58 & 2.12 & 5.71 & 5.63 & 5.42 & 2.78 \\
\hline Total HF & -5.32 & 29.60 & 15.94 & -6.87 & -14.78 & 13.88 & 13.34 & 11.21 & -12.02 \\
\hline Total SAPT0 & -15.44 & -29.33 & -37.02 & -19.33 & -30.03 & -27.00 & -27.11 & -30.47 & -30.79 \\
\hline Disp./electost. & 0.89 & 3.98 & 2.03 & 0.70 & 0.51 & 2.22 & 2.20 & 1.92 & 0.57 \\
\hline
\end{tabular}

dominating dispersion character arising from the parallel displaced interaction with the large displacement of about $6 \AA$. Among the DASQ dimers, the highest SAPT0 stability is observed for the three systems: (b), (e) and (f) panels in Fig. 3. The first and the last of them posses the strong electrostatic contribution and are bonded by the hydrogen 
Table 6 SAPT0/aug-ccpVDZ interaction energy decomposition for DMASQ and DASQ frozen dimers (in kcal/ mol)

\begin{tabular}{|c|c|c|c|c|c|c|c|c|}
\hline \multirow[t]{2}{*}{ Component } & \multicolumn{5}{|l|}{ DMASQ } & \multicolumn{3}{|l|}{ DASQ } \\
\hline & $\mathrm{Hb}$ & s3 & s6 & $\mathrm{z} 3$ & $\mathrm{z} 6$ & $\mathrm{Hb}-\mathrm{s}$ & $\mathrm{s}$ & $\mathrm{z}$ \\
\hline Electrostatics & -10.00 & -18.08 & -24.81 & -17.57 & -6.64 & -28.81 & -16.11 & -16.48 \\
\hline $\mathrm{E}_{\mathrm{elst}, r}^{(10)}$ & -10.00 & -18.08 & -24.81 & -17.57 & -6.64 & -28.81 & -16.11 & -16.48 \\
\hline Exchange & 12.14 & 60.63 & 50.99 & 59.63 & 7.85 & 33.35 & 32.49 & 30.56 \\
\hline $\mathrm{E}_{\text {exch }}^{(10)}$ & 12.14 & 60.63 & 50.99 & 59.63 & 7.85 & 33.35 & 32.49 & 30.56 \\
\hline $\mathrm{E}_{\mathrm{exch}}^{(10)}\left(\mathrm{S}^{2}\right)$ & 12.10 & 60.44 & 50.89 & 59.45 & 7.85 & 33.10 & 32.39 & 30.48 \\
\hline Induction & -4.81 & -7.31 & -7.40 & -7.28 & -2.15 & -12.75 & -3.25 & -3.41 \\
\hline $\mathrm{E}_{\mathrm{ind}, r}^{(20)}$ & -5.40 & -26.49 & -23.49 & -25.94 & -3.53 & -14.01 & -16.37 & -16.48 \\
\hline $\mathrm{E}_{\mathrm{exch}-\mathrm{ind}, r}^{(20)}$ & 2.30 & 24.11 & 20.97 & 23.58 & 2.15 & 6.79 & 15.10 & 15.19 \\
\hline$\delta_{r}^{H F}(2)$ & -1.71 & -4.92 & -4.88 & -4.92 & -0.76 & -5.53 & -1.98 & -2.12 \\
\hline Dispersion & -10.28 & -62.43 & -53.11 & -61.99 & -19.67 & -17.89 & -38.79 & -36.32 \\
\hline $\mathrm{E}_{\mathrm{disp}}^{(20)}$ & -11.48 & -71.54 & -60.95 & -70.98 & -21.03 & -20.43 & -44.03 & -41.33 \\
\hline $\mathrm{E}_{\mathrm{exch}-\mathrm{disp}}^{(20)}$ & 1.19 & 9.11 & 7.84 & 8.98 & 1.36 & 2.54 & 5.24 & 5.01 \\
\hline Total HF & -2.67 & 35.24 & 18.78 & 34.77 & -0.94 & -8.21 & 13.13 & 10.66 \\
\hline Total SAPT0 & -12.95 & -27.19 & -34.34 & -27.22 & -20.62 & -26.10 & -25.66 & -25.66 \\
\hline Disp./electost. & 1.03 & 3.45 & 2.14 & 3.53 & 2.96 & 0.62 & 2.41 & 2.20 \\
\hline
\end{tabular}

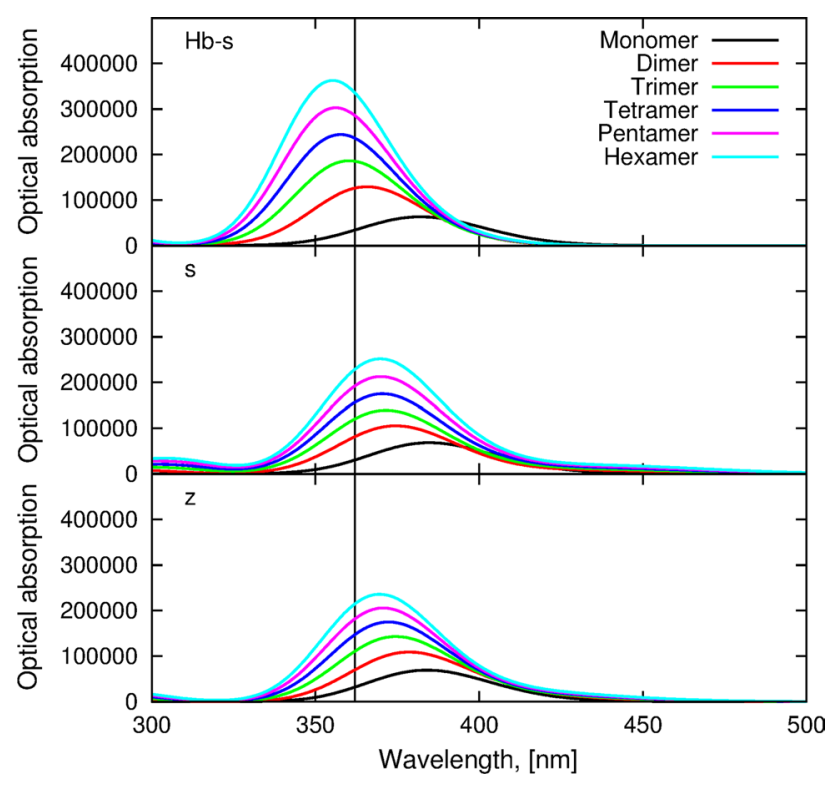

Fig. 13 Influence of aggregation on the optical absorption of DASQ in the gas phase (PBE0/cc-pVDZ data). Black solid line denotes the reference monomer spectrum, and the vertical line corresponds to the experimental measured maximum wavelength in chloroform

bonds. The (e) dimer is built of the two perpendicular molecules with one of them "wrapped" about the other and is characterized by the prevailing dispersion interaction (dispersion to electrostatic ratio equal to 1.92 ).

\section{Aggregation influence on the optical absorption}

An experimental maximum absorption wavelength measured in chloroform is equal to 362 and $630 \mathrm{~nm}$, respectively, for DASQ and DMASQ [43]. Theoretical PBE0/ cc-pVDZ wavelength for DASQ exhibits the satisfactory agreement with experiment, particularly when taking into account the applied simplifications such as an omission of the solvent effects in calculations or vertical absorption. However, the experiment-theory difference for DMASQ is large (calculated monomer maximum absorption wavelength varying from 520 to $524 \mathrm{~nm}$ depending on the geometry). This discrepancy arises from the intrinsic errors in DFT and although striking as the absolute value, it does still allow to investigate the relative changes in the spectrum upon interactions [30].

Moreover, one needs to remember that the vertical absorption calculations as performed here do not reproduce any information about the shape of the spectral lines. It only gives the position and the intensity of the signal. Therefore, all the contours on Fig. 13 correspond simply to gaussian fits of the calculated data. The good source of the information on the precise shape of the aggregate lines could be obtained with the coherent electron scattering (CES) approximation [38-42]. It is particularly useful in the case of the strong vibrational coupling that cannot be properly described by the simple electronic theory. 
Table 7 Most intensive transition wavelengths $(\mathrm{nm})$, oscillator strength and the corresponding molecular orbitals for DASQ (signals with the oscillator strengths larger than 0.5 and wavelengths longer than $300 \mathrm{~nm}$ are given)

\begin{tabular}{lllll}
\hline Aggregate & Wavelength & Oscillator strength & Orbitals & Percent \\
\hline Hb-s & & & & \\
Monomer & 382 & 0.87 & HOMO $\rightarrow$ LUMO & 97 \\
Dimer & 365 & 1.76 & HOMO $\rightarrow$ LUMO +1 & 59 \\
$\quad$ Hexamer & 354 & 4.61 & HOMO $-5 \rightarrow$ LUMO +1 & 28 \\
s & & & & \\
Monomer & 385 & 0.94 & HOMO $\rightarrow$ LUMO & 99 \\
Dimer & 374 & 1.45 & HOMO $-1 \rightarrow$ LUMO +1 & 77 \\
Hexamer & 369 & 2.70 & HOMO $-4 \rightarrow$ LUMO +4 & 17 \\
z & & & HOMO $\rightarrow$ LUMO & 99 \\
Monomer & 384 & 0.96 & HOMO $-1 \rightarrow$ LUMO +1 & 73 \\
Dimer & 378 & 1.49 & HOMO $-3 \rightarrow$ LUMO +1 & 27 \\
Hexamer & 369 & 1.10 & HOMO $-5 \rightarrow$ LUMO +5 & 20 \\
& 368 & 1.47 & & \\
\hline
\end{tabular}

Here, the accent is placed on the shift of the position

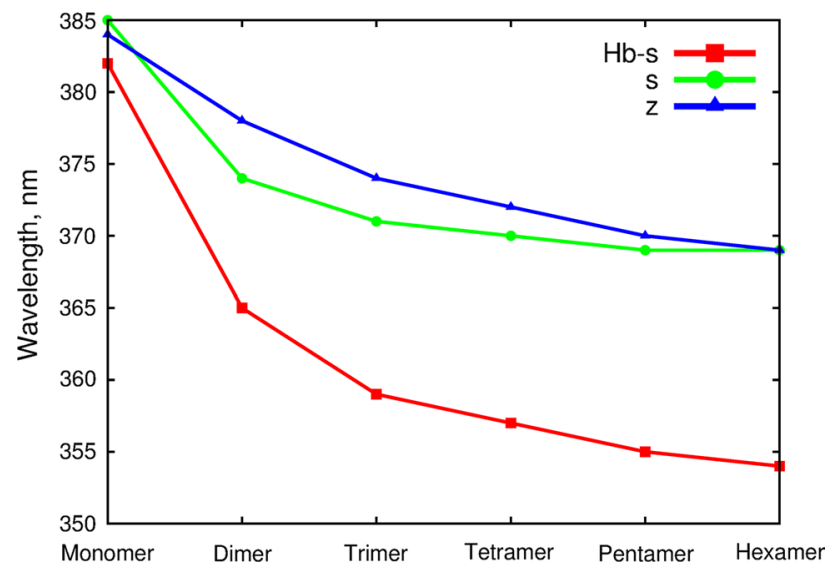

Fig. 14 Influence of aggregation on the maximal wavelength for optical absorption of DASQ in the gas phase (PBE0/cc-pVDZ data)

(a)
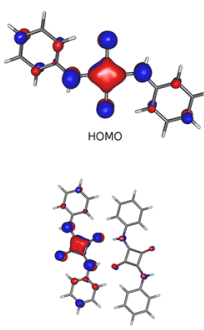

номо

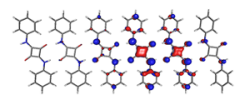

номо-5
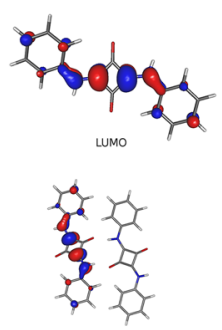

wno+1

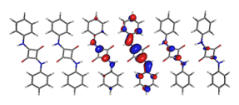

LUMO+1 (b)
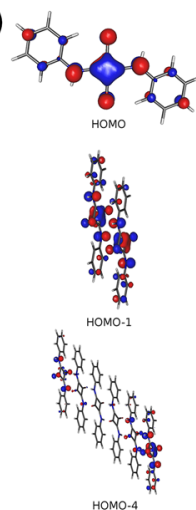

of the spectral lines of squaraines induced by the intermolecular interactions, and not on the shape and the vibrational structure of the signals. Therefore, Fig. 13 presents the optical absorption spectra calculated with the PBE0/ cc-pVDZ approach for various non-relaxed oligomers of DASQ.

The signals do not vary much for DASQ oligomers of all the analyzed types. For each system, only one intensive signal is observed (with the oscillator strength larger than 0.5). Generally, the elongation of the oligomeric system brings about the decrease in the maximum absorption wavelength together with the increase in the intensity of the transition. In the case of the Hb-s oligomers, the corresponding wavelength decreases from $382 \mathrm{~nm}$ for monomer to 354 for hexamer (see Fig. 14; Table 7). The corresponding

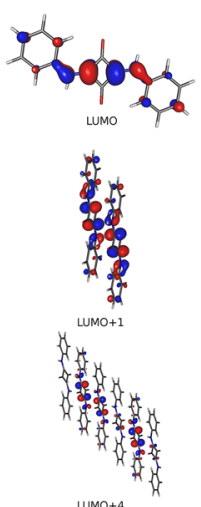

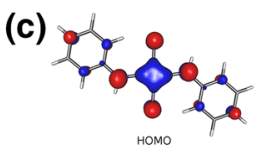
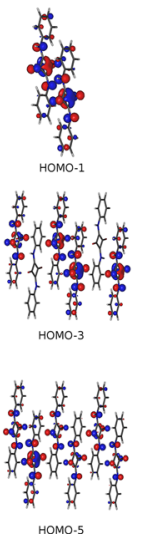
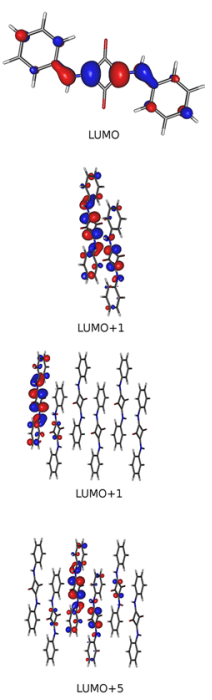

Fig. 15 Frontier orbitals involved in most intensive transitions for DASQ a Hb-s, b s and c z monomers, dimers and hexamers (PBE0/cc-pVDZ data) 

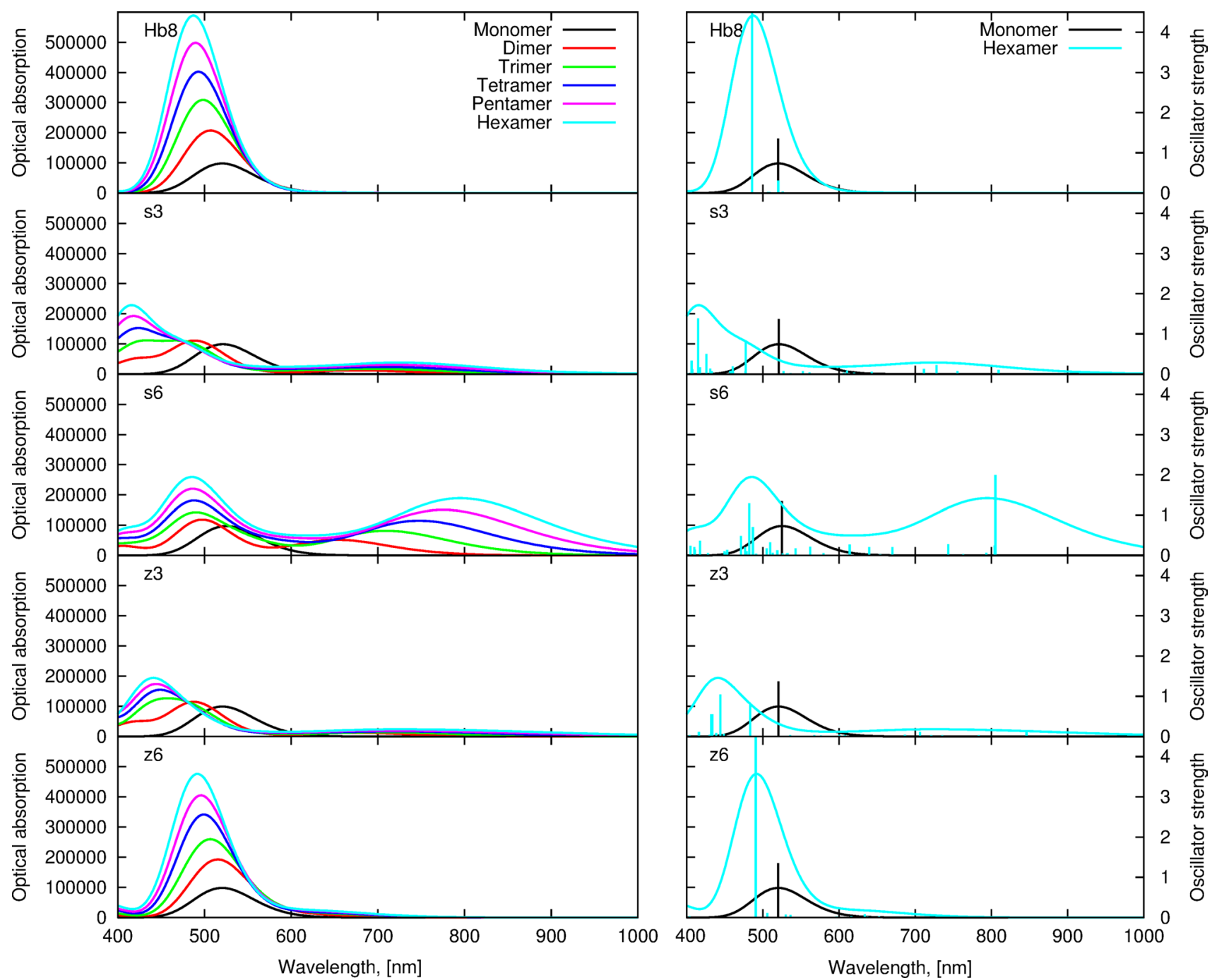

Fig. 16 Influence of aggregation on the optical absorption of DMASQ in the gas phase (PBE0/cc-pVDZ data). Black solid line denotes the reference monomer spectrum. Left panel presents the

tendency for the $\mathrm{s}$ and $\mathrm{z}$ oligomers is very similar with the wavelength shifts of 28 and $15 \mathrm{~nm}$ for Hb-s and $\mathrm{z}$ oligomers, respectively. As can be noticed on Fig. 14, one should not expect a significant wavelength change with the further elongation of the oligomers in the case of the s-type systems and only small changes (probably not exceeding $5 \mathrm{~nm}$ ) for the remaining oligomers. The exemplary molecular orbitals involved in the most intensive transitions for $\mathrm{Hb}$-s DASQ monomer, dimer and hexamer are depicted in Fig. 15. One can see that the most intensive transitions for $\mathrm{Hb}$-s and s oligomers involve orbitals localized in the same part of the oligomer, thus avoiding the large intermolecular charge transfer (Fig. 15).

On the other hand, the situation is slightly more complicated for DMASQ. Here, the hydrogen-bonded systems (Hb8) behave similarly to the DASQ oligomers-the only gaussian fit for all the oligomers and right panel-the monomer and hexamer calculated signals with the corresponding oscillator strengths (stics) and the fit

effects of chain elongation up to hexamer are a decrease in the maximum absorption wavelength by $35 \mathrm{~nm}$ and an increase in the oscillator strength (by more than 5.8 times, compare Fig. 16). However, in the case of the $\mathrm{z} 6$ oligomers, also the general shape of the spectrum remain unchanged with the chain lengthening and the $\lambda_{\max }$ decrease (by $30 \mathrm{~nm}$ ) and oscillator strength increase (by more than 4.7 times) can be noticed, but additionally very weak signals above $620 \mathrm{~nm}$ appear (oscillator strength of 0.05-0.15). Another group of oligomers consists of $\mathrm{s} 3$ and $\mathrm{z} 3$ chains. For these systems, the decrease in the maximum absorption wavelength is significantly larger than for $\mathrm{Hb} 8$ and $\mathrm{z} 6$ oligomers (106 and $76 \mathrm{~nm}$, respectively), and the intensity of the maximum signal undergoes only minor modifications. Moreover, for s3 and z3 oligomers, the long-wave part of the spectrum becomes more pronounced than in the case 


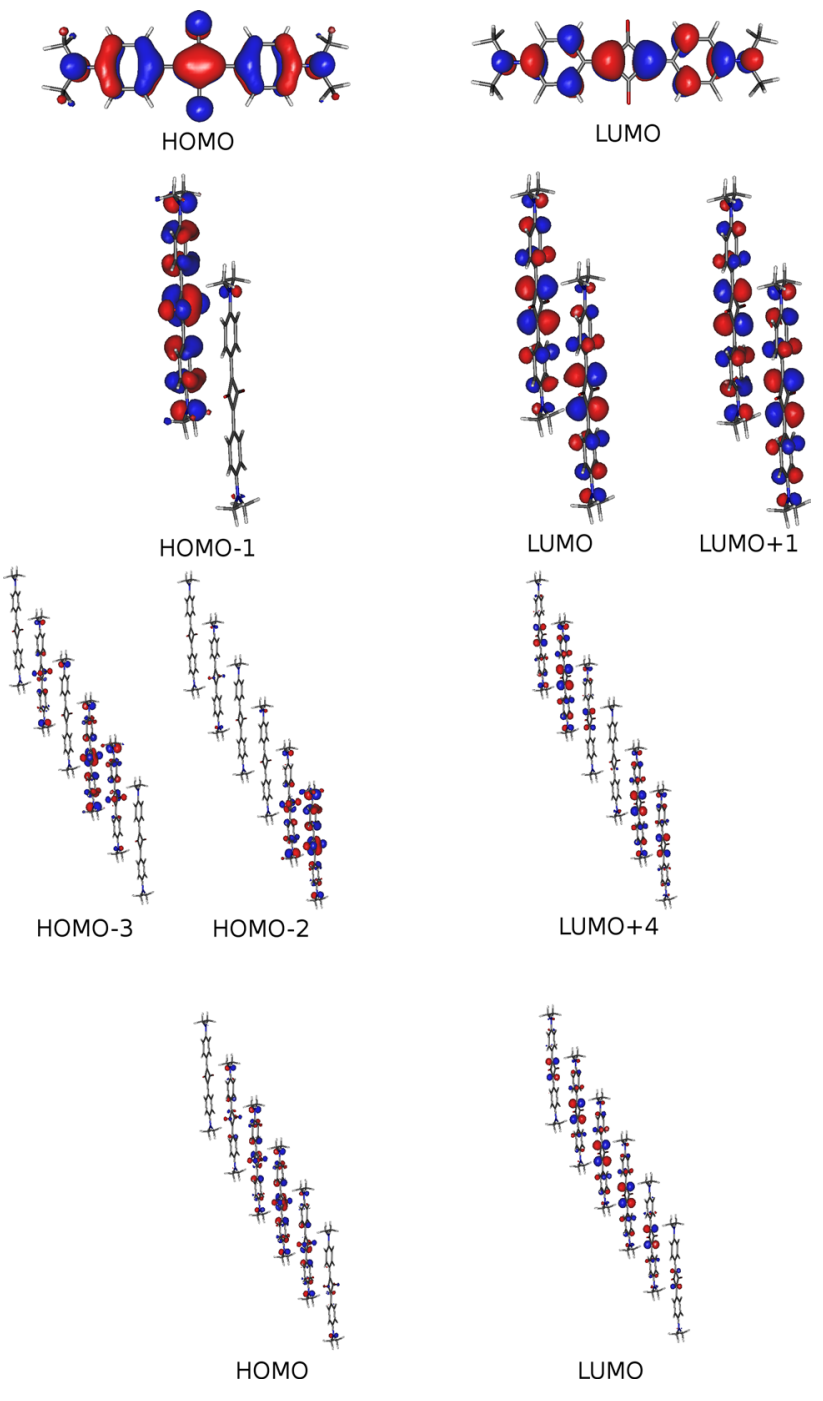

Fig. 17 Frontier orbitals involved in most intensive transitions for DMASQ s6 monomers, dimers and hexamers (PBE0/cc-pVDZ data)

of z6, although still only signals of small intensity arise above $650 \mathrm{~nm}$. The similar modification of the absorption spectrum for $\mathrm{s} 3$ and $\mathrm{z} 3$ oligomers agrees well with the very much alike interaction energy components for both types of chains (see Table 6). The qualitative change of the spectrum shape with respect to the above analyzed systems is observed in the case of s6 DMASQ oligomers. The intensive signal is shifted here by $42 \mathrm{~nm}$ with the chain extension from monomer to hexamer, yet another more intensive transition above $600 \mathrm{~nm}$ emerges. This signal, on the contrary, is shifted to the longer wavelength (by $152 \mathrm{~nm}$-from $653 \mathrm{~nm}$ for the dimer to $805 \mathrm{~nm}$ for the hexamer), and the increase in its oscillator strength can be noticed by 2.8 times. Figure 17 presents the frontiers orbitals of DMASQ involved in the most intensive transitions for monomer, dimer and hexamer of the s6 oligomer. The corresponding wavelengths and oscillator strengths for all the s6 oligomers are presented in Supplementary Information. In the dimer, the long-wavelength signal (at $653 \mathrm{~nm}$ ) arises from the HOMO-1 to LUMO transition, and the most intensive transition at $496 \mathrm{~nm}$ involves mostly HOMO-1 and LUMO+1 orbitals. While in the HOMO-1 orbital the electron density is concentrated at one molecule, the LUMO and LUMO+1 orbitals are characterized by the symmetric charge density distribution between both units. This picture is more complicated for the s6 hexamer due to the complexity of the oligomer, but only small shifts of the electron density can be observed for HOMO $\rightarrow$ LUMO transition at $805 \mathrm{~nm}$ and slightly more pronounced for HOMO- $2 \rightarrow$ LUMO +4 at $482 \mathrm{~nm}$. Similar situation with no drastic electron density redistribution upon excitation, but only mild displacement, is noticed for the remaining oligomers.

\section{Summary}

Aggregation phenomenon of two squaraine dyes DASQ and DMASQ is investigated with computational tools of quantum chemistry. The two molecules are chosen since they are prone to the different extent to the hydrogen-bond formation. The potential energy scan for dimers, trimers and tetramers indicates some regular staircase and zig-zag structures that are further investigated as frozen oligomeric chains in order to analyze an influence of the aggregation and the nature of the interactions on the absorption spectrum.

Interaction energy decomposition for dimers indicates the numerous dimers of the purely dispersion character for both DASQ and DMASQ molecules. Also for the larger DMASQ oligomers, the dispersion interactions seem to lead to the stable systems with the most attractive intermolecular forces. However, the full search of the potential energy surface for DASQ brings also the hydrogen-bonded structures as those exhibiting the highest supermolecular interaction energy. This different susceptibility for the hydrogen-bond formation resulting from the different functional groups arrangement causes the different calculationsexperiment agreement for both analyzed systems: The absorption spectrum for DASQ agrees well with experiment with almost any choice of the methodology, while for DMASQ the agreement for the monomer is weak and the error exceeds $100 \mathrm{~nm}$ in most cases independently on the approach chosen. The improvement of the basis set, the change of the DFT functional or inclusion of the solutesolvent interactions [43] improves the obtained absorption wavelength not more than by a dozen of $\mathrm{nm}$ confirming the conclusion of Laurent and Jacquemin that this is the intrinsic DFT error [30].

The addition of the influence of the intermolecular interactions into the investigation of the absorption spectrum 
for squaraines shows the shift of the maximum absorption wavelength and the increase in the intensity of the signal with the elongation of the chain length and the new signals appearing in the long-wavelength part of the spectrum for DMASQ. The obtained computational effects of aggregation on the absorption spectrum comply well with the aggregation manifestation in the experiment: the signal shift and broadening [11, 18-20].

Acknowledgments The project was supported from the funds of Ministry of Science and Higher Education of Poland, Grant Number: IP2012034472. Wroclaw Networking and Supercomputing Centre, Poznan Supercomputing and Networking Center and AGH Cyfronet Krakow are gratefully acknowledged for the generous allotment of computational resources.

Open Access This article is distributed under the terms of the Creative Commons Attribution 4.0 International License (http://creativecommons.org/licenses/by/4.0/), which permits unrestricted use, distribution, and reproduction in any medium, provided you give appropriate credit to the original author(s) and the source, provide a link to the Creative Commons license, and indicate if changes were made.

\section{References}

1. Kasha M, Rawls HR, Ashraf El-Bayoumi M (1965) The exciton model in molecular spectroscopy. Pure Appl Chem 11:371-392

2. Würthner F, Kaiser TE, Saha-Möller ChR (2011) J-aggregates: from serendipitous discovery to supramolecular engineering of functional dye materials. Angew Chem Int Ed 50:3376-3410

3. Grieschner J, Park SY (2013) Luminescent distyrylbenzenes: tailoring molecular structure and crystalline morphology. J Mater Chem C 1:5818-5832

4. Chen G, Sasabe H, Lu W, Wang X-F, Kido J, Hong Z, Yang Y (2013) J-aggregation of a squaraine dye and its application in organic photovoltaic cells. J Mater Chem C 1:6547-6552

5. Spencer S, Hu H, Li Q, Ahn H-Y, Qaddoura M, Yao S, Ioannidis A, Belfield K, Collison CJ (2014) Controlling J-aggregate formation for increased short-circuit current and power conversion efficiency with a squaraine donor. Prog Photovolt 22:488-493

6. Mayerhöffer U, Würthner F (2012) Cooperative self-assembly of squaraine dyes. Chem Sci 3:12151220

7. Zhang Y, Kim B, Yao S, Bondar MV, Belfield KD (2013) Controlled aggregation and enhanced two-photon absorption of a water-soluble squaraine dye with a poly(acrylic acid) template. Langmuir 29:11005-11012

8. Zheng C, Penmetcha AR, Cona B, Spencer SD, Zhu B, Heaphy P, Cody JA, Collison CJ (2015) Contribution of aggregate states and energetic disorder to a squaraine system targeted for organic photovoltaic devices. Langmuir 31:7717-7726

9. de Miguel G, Ziółek M, Zitnan M, Organero JA, Pandey SS, Hayase S, Douhal A (2012) Photophysics of H- and J-aggregates of indole-based squaraines in solid state. J Phys Chem C 116:9379-9389

10. Dimitriev OP, Dimitrieva AP, Tolmachev AI, Kurdyukov VV (2005) Solvent-induced organization of squaraine dyes in solution capillary layers and adsorbed films. J Phys Chem B 109:4561-4567

11. Deing KC, Mayerhöffer $\mathrm{U}$, Würthner $\mathrm{F}$, Meerholz $\mathrm{K}$ (2012) Aggregation-dependent photovoltaic properties of squaraine/ $\mathrm{PC}_{61} \mathrm{BM}$ bulk heterojunctions. Phys Chem Chem Phys 14:8328-8334

12. Zhai D, Xu W, Zhang L, Chang Y-T (2014) The role of "disaggregation" in optical probe development. Chem Soc Rev 43:2402-2411

13. Li X-H, Zhang B-W, Cao Y (2000) Aggregation of bis(2,4,6trihydroxyphenyl) squaraine in different solutionAggregation of bis(2,4,6-trihydroxyphenyl) squaraine in different solutionss. Dyes Pigm 45:209-217

14. Kuster S, Geiger T (2015) Coupled $\pi$-conjugated chromophores: squaraine dye dimers as two connected pendulums. Dyes Pigm 113:110-116

15. Yan Z, Xu H, Guang S, Zhao X, Fan W, Liu XY (2012) A convenient organic-inorganic hybrid approach toward highly stable squaraine dyes with reduced $\mathrm{H}$-aggregation. Adv Funct Mater 22:345-352

16. Patsenker LD, Tatarets AL, Terpetschnig EA (2010) Long-wavelength probes and labels based on cyanines and squaraines. In: Demchenko AP (ed) Advanced fluorescence reporters in chemistry and biology I: fundamentals and molecular design. Springer series fluorescence, vol 8. Springer, Berlin, Heidelberg, p 65

17. Qin C, Wong W-Y, Han L (2013) Squaraine dyes for dye-sensitized solar cells: recent advances and future challenges. Chem Asian J 8:1706-1719

18. Yefimova S, Lebed A, Sorokin A, Guralchuk G, Borovoy I, Malyukin Y (2012) J-type aggregation of squaraine dye Sq-2Me in surfactant solutions. J Mol Liq 165:113-118

19. McKerrow AJ, Buncel E, Kazmaier PM (1995) Aggregation of squaraine dyes: structure-property relationships and solvent effects. Can J Chem 73:1605-1615

20. Chen H, Farahat MS, Law K-Y, Whitten DG (1996) Aggregation of surfactant squaraine dyes in aqueous solution and microheterogeneous media: correlation of aggregation behavior with molecular structure. J Am Chem Soc 118:2584-2594

21. Wang X, Xu J, Li M, Fang D, Chen B, Wang L, Xu W (2013) Highly efficient unsymmetrical squaraines for panchromatic dye-sensitized solar cells: a computational study. RSC Adv 3:5227-5237

22. Al-Fahdan NS, Asiri AM, Irfan A, Basaif SA, El-Shishtawy RM (2014) An electro-optical and electron injection study of benzothiazole-based squaraine dyes as efficient dye-sensitized solar cell materials: a first principles study. J Mol Model 20:2517

23. Asiri AM, Al-Horaibi SAH, Irfan A, Basaif SA, El-Shishtawy RM (2015a) Cis/Trans geometric effect on the electro-optical properties and electron injection in indole-based squaraine sensitizers: quantum chemical investigations. Int J Electrochem Sci 10:1529-1542

24. Asiri AM, Al-Horaibi SAH, Irfan A, Basaif SA, El-Shishtawy RM (2015b) Comparative study of the structural, electronic and charge transport properties of benzothiazole- and indole-based squaraine sensitizers. Int J Electrochem Sci 10:1822-1832

25. Alberto ME, Mazzone G, Quartarolo AD, Sousa FFR, Sicilia E, Russo N (2014) Electronic spectra and intersystem spinorbit coupling in 1,2- and 1,3-squaraines. J Comp Chem 35:2107-2113

26. Puyad AL, Chaitanya GK, Prabhakar C, Bhanuprakash K (2013) A comparative study of semi-squaraine and squaraine dyes using computational techniques: tuning the charge transfer/biradicaloid character by substitution. J Mol Model 19:275-287

27. Xu J, Zhang H, Wang L, Liang G, Wang L, Shen X, Xu W (2010) DFT and TD-DFT studies on symmetrical squaraine dyes for nanocrystalline solar cells. Monatsh Chem 141:549-555

28. Silva CE, Dos Santos HF, Speziali NL, Diniz R, de Oliveira LFC (2010) Role of the substituent effect over the squarate oxocarbonic ring: spectroscopy, crystal structure, and density functional 
theory calculations of 1,2-Dianilinosquairane. J Phys Chem A 114:10097-10109

29. Rocca D, Gebauer R, De Anglelis F, Nazeeruddin MK, Baroni S (2009) Time-dependent density functional theory study of squaraine dye-sensitized solar cells. Chem Phys Lett 475:49-53

30. Jacquemin D, Perpéte EA, Laurent AD, Assfeld X, Adamo C (2009) Spectral properties of self-assembled squarainetetralactam: a theoretical assessment. Phys Chem Chem Phys 11:1258-1262

31. Frisch MJ, Trucks GW, Schlegel HB, Scuseria GE, Robb MA, Cheeseman JR, Scalmani G, Barone V, Mennucci B, Petersson GA, Nakatsuji H, Caricato M, Li X, Hratchian HP, Izmaylov AF, Bloino J, Zheng G, Sonnenberg JL, Hada M, Ehara M, Toyota K, Fukuda R, Hasegawa J, Ishida M, Nakajima T, Honda Y, Kitao O, Nakai H, Vreven T Jr, Montgomery JA, Peralta JE, Ogliaro F, Bearpark M, Heyd JJ, Brothers E, Kudin KN, Staroverov VN, Kobayashi R, Normand J, Raghavachari K, Rendell A, Burant JC, Iyengar SS, Tomasi J, Cossi M, Rega N, Millam JM, Klene M, Knox JE, Cross JB, Bakken V, Adamo C, Jaramillo J, Gomperts R, Stratmann RE, Yazyev O, Austin AJ, Cammi R, Pomelli C, Ochterski JW, Martin RL, Morokuma K, Zakrzewski VG, Voth GA, Salvador P, Dannenberg JJ, Dapprich S, Daniels AD, Farkas Ö, Foresman JB, Ortiz JV, Cioslowski J, Fox DJ (2009) Gaussian 09 revision A.1. Gaussian Inc., Wallingford CT

32. Turney JM, Simmonett AC, Parrish RM, Hohenstein EG, Evangelista FA, Fermann JT, Mintz BJ, Burns LA, Wilke JJ, Abrams ML, Russ NJ, Leininger ML, Janssen CL, Seidl ET, Allen WD, Schaefer HF, King RA, Valeev EF, Sherrill CD, Crawford TD (2012) Psi4: an open-source ab initio electronic structure program. WIREs Comput Mol Sci 2:556-565

33. Jeziorski B, Moszynski R, Szalewicz K (1994) Perturbation theory approach to intermolecular potential energy surfaces of van der Waals complexes. Chem Rev 94:1887-1930
34. Hohenstein EG, Sherrill CD (2010) Density fitting and Cholesky decomposition approximations in symmetry-adapted perturbation theory: implementation and application to probe the nature of $\pi-\pi$ interactions in Linear Acenes. J Chem Phys 132:184111

35. Hohenstein EG, Parrish RM, Sherrill CD, Turney JM, Schaefer HF (2011) Large-scale symmetry-adapted perturbation theory computations via density fitting and laplace transformation techniques: investigating the fundamental forces of DNA-intercalator interactions. J Chem Phys 135:174017

36. Holroyd LF, van Mourik T (2007) Insufficient description of dispersion in B3LYP and large basis set superposition errors in MP2 calculations can hide peptide conformers. Chem Phys Lett 442:42-46

37. Koch W, Holthausen MC (2008) A chemist's guide to density functional theory. Wiley-VCH, Wienheim

38. Eisfeld A, Briggs JS (2002) The J-band of organic dyes: lineshape and coherence length. Chem Phys 281:61-70

39. Eisfeld A, Briggs JS (2006) The J- and H-bands of organic dye aggregates. Chem Phys 324:376-384

40. Roden J, Eisfeld A, Briggs JS (2008) The J- and H-bands of dye aggregate spectra: analysis of the coherent exciton scattering (CES) approximation. Chem Phys 352:258-266

41. Roden J, Schulz G, Eisfeld A, Briggs JS (2009) Electronic energy transfer on a vibronically coupled quantum aggregate. $\mathrm{J}$ Chem Phys 131:044909

42. Roden J, Strunz WT, Eisfeld A (2010) Spectral properties of molecular oligomers. A non-Markovian quantum state diffusion approach. Int J Mod Phys B 24:5060-5067

43. Kaczmarek-Kędziera A, Ziegler-Borowska M, Chełminiak D, Kuchnicki P, Kaczmarek H (2015) Effect of UV-irradiation on spectral properties of squaraine dye in diluted solutions. J Photochem Photobiol A. doi:10.1016/j.jphotochem.2015.11.011 